Review

\title{
Surgical and systemic therapies for addressing occult disease in advanced epithelial ovarian cancer
}

\author{
Aditi Bhatt ${ }^{1, *}$, Snita Sinukumar ${ }^{2}$, Praveen Kammar ${ }^{3}$, Sanket Mehta ${ }^{3}$ \\ ${ }^{1}$ Department of Surgical Oncology, Zydus Hospital, 380054 Ahmedabad, India \\ ${ }^{2}$ Department of Surgical Oncology, Jehangir Hospital, 411001 Pune, India \\ ${ }^{3}$ Department of Surgical Oncology, Saifee Hospital, 400004 Mumbai, India \\ *Correspondence: aditimodi31@gmail.com (Aditi Bhatt) \\ Academic Editor: Enrique Hernandez \\ Submitted: 16 September 2021 Revised: 29 October 2021 Accepted: 1 November 2021 Published: 15 February 2022
}

\begin{abstract}
The incidence of peritoneal recurrence in advanced epithelial ovarian cancer (EOC) is high and could be attributed to the high prevalence of occult disease the persists despite complete cytoreductive surgery (CRS) and systemic chemotherapy. Several therapeutic approaches have been used to address such occult disease. Hyperthermic intraperitoneal chemotherapy (HIPEC) acts on microscopic disease as well as free intraperitoneal cancer cells shed during surgery, thus, reducing the risk of recurrence. Maintenance therapies like Poly ADPRibosyl Polymerase (PARP) inhibitors and the anti-angiogenic agent bevacizumab are used as maintenance therapies to delay recurrence. The most definitive way to eradicate such occult disease completely is resection of the peritoneum. The high preponderance of occult disease in the parietal peritoneum and some regions of the visceral peritoneum has led some surgeons to investigate the role of a total parietal peritonectomy (TPP) performed along with wide resection of the visceral peritoneum as a strategy for addressing occult disease. The mechanism of action differs from that of HIPEC and systemic therapies. It is possible that the benefit of each of these therapies is additive. EOC is a heterogeneous disease with a number of clinicopathological and molecular factors influencing the prognosis. There are likely to be different subgroups of patients that benefit from each of these 4 therapies or a combination of these. In this manuscript, we review the rationale and current evidence for the use of each of these therapies and discuss the potential role of a TPP in light of other therapies.
\end{abstract}

Keywords: Advanced ovarian cancer; Cytoreductive surgery; Total parietal peritonectomy; HIPEC; PARP inhibitors; Anti-angiogenic therapy

\section{Introduction}

Advanced epithelial ovarian cancer (EOC) remains an incurable disease with high recurrence rates despite advances in locoregional and systemic therapies [1]. Most of the recurrences are in the peritoneum and the disease remains confined to the peritoneum for prolonged periods [2]. This could be attributed to the high incidence of occult disease in EOC.

Several locoregional and systemic therapeutic approaches have been used to address such occult disease [3]. Hyperthermic intraperitoneal chemotherapy (HIPEC) acts on microscopic disease as well as free intraperitoneal cancer cells shed during surgery, thus, reducing the risk of recurrence [4]. The addition of HIPEC to interval cytoreductive surgery (CRS) showed a benefit in both progression-free and overall survival over interval CRS alone. The benefit of HIPEC in addition to primary CRS is being evaluated in clinical trials [5]. Maintenance therapies like Poly ADP-Ribosyl Polymerase (PARP) inhibitors and the antiangiogenic agent bevacizumab have the potential to delay recurrence and prolong survival [3]. These therapies act on both systemic and intraperitoneal disease. Bevacizumab has shown a survival benefit only in patients with subopti- mal debulking surgery and those with stage IV-A disease. PARP inhibitors are recommended for patients with BRCA mutations and/or homologous repair deficiency (HRD) following completion of first-line therapy [6].

The most definitive way to eradicate occult disease completely is resection of the peritoneum. The parietal peritoneum and some visceral peritoneal sites are more prone to harboring occult disease in patients undergoing interval CRS and visual inspection is inaccurate in predicting the presence or absence of residual disease [7]. Complete resection of the parietal peritoneum or a total parietal peritonectomy (TPP) performed along with wide resection of the visceral peritoneum could be an effective strategy for addressing this occult disease. The mechanism of action differs from that of other locoregional therapies like HIPEC and systemic therapies and thus, it is possible that the benefit of each of these therapies is additive. In this manuscript, we review the rationale and current evidence for the use of each of these therapies and discuss the potential role of a TPP in light of other therapies. The pathways of peritoneal spread and disease distribution in the peritoneal cavity, response to systemic therapy which form the basis of formulating therapeutic strategies are described and discussed. 


\section{Peritoneal dissemination and response to systemic chemotherapy}

\subsection{Patterns of spread in ovarian cancer}

An understanding and knowledge of patterns of peritoneal spread is vital to the treatment of ovarian cancer. Peritoneal spread includes the mode of peritoneal dissemination and the actual distribution of disease in the peritoneal cavity. Peritoneal dissemination occurs through the transcoelomic or transmesothelial route, the translymphatic route and the haematogenous route. In the first two routes, single cells or clusters of cells are shed from the tumor spontaneously, due to surgical manipulation or spontaneous or iatrogenic rupture and gain access to the peritoneal cavity $[8,9]$. In transmesothelial spread, these free intraperitoneal cells attach to the peritoneum, breach the mesothelial barrier and reach the submesothelial tissue where they proliferate [10]. In translymphatic spread, the tumor cells reach the subperitoneal tissue through the lymphatic stomata. Anatomical regions in the peritoneal cavity with a high concentration of lymphatic stomata like the greater omentum, appendices epiploicae of the colon, inferior surface of the diaphragm, falciform ligament, the recto-uterine pouch and small bowel mesentery are more frequently involved compared to other sites in this pathway $[11,12]$. Both transmesothelial and translymphatic spread occur in EOC.

Some tumors employ the same pathways for peritoneal spread but the actual distribution of disease in the peritoneal cavity differs which could be attributed to the inherent disease biology [13]. For example, with transmesothelial spread it may be expected that the pattern of distribution in EOC is random proximal distribution, in which peritoneal spread occurs in vicinity of the tumor.

However, it has been observed that the parietal peritoneum is involved first and disease follows the pattern of redistribution [14]. Based on the information derived from experimental studies and few clinical studies, cancer spread in ovarian cancer could be best described as wide-spread cancer distribution (Fig. 1). Ascites is seen early in EOC. Pelvic ascites is staged as IC disease and causes redistribution of cancer cells. Certain sites are involved early in the course of peritoneal spread like the omentum, pelvic peritoneum, right paracolic gutter and right subphrenic peritoneum [15].

Clinical studies on the disease distribution in EOC are few and have several limitations.

In a retrospective study of 214 patients with EOC (67.7\% with serous carcinoma; nearly $90 \%$ has stage III and IV disease) the pelvic peritoneum was the commonest site to be involved, followed by the colon and then the diaphragm [16]. In a prospective multi-centric study, it was shown EOC involved the lower regions (regions 5, 6 and 7 according to the description in Sugarbaker's peritoneal cancer index) first, followed by the middle regions $(0,4,8$ mainly the omentum) and then the upper regions $(1,2,3)$ [14]. None of the patients had involvement of the upper re- gions without involvement of the lower regions. The small bowel was the last site to be involved. Disease on the small bowel surface and mesentery was not seen in the absence of disease in all three regions of the peritoneal cavity. Ninetyfive percent of the patients in this study had serous EOC. A more detailed evaluation of the patterns of peritoneal spread could guide surgical resection in advanced EOC.

\subsection{Presence of microscopic disease in 'normal appearing' peritoneum}

In early stage disease random peritoneal biopsies lead to upstaging in $18 \%$ of the patients [17]. There are very few studies looking at the incidence of occult disease in patients with advanced EOC undergoing primary CRS. Our preliminary study showed this incidence to be $50 \%$ (unpublished results). Azaïs et al. [18] prospectively evaluated the incidence of microscopic disease in the unresected peritoneum at the end of CRS in 26 patients with advanced, high-grade serous EOC. Biopsies were taken from 13 regions in each patient and $26.9 \%$ had occult disease in one or more regions. After mathematical analysis, the probability that microscopic disease remained after complete macroscopic CRS in patients with EOC was 98.14\% [18].

In patients receiving neoadjuvant chemotherapy (NACT), the reported incidence of occult disease ranges from $13-45 \%$ [14,19]. The incidence of occult disease around tumor nodules was $46 \%$ and that in regions that show no tumor nodules was $35 \%$ in our prospective study [20]. It has been hypothesized that residual disease after NACT harbors chemotherapy resistant stem cells which if not removed increase the risk of recurrence [21]. One study showed a higher incidence of platinum resistant recurrence and a shorter progression-free survival (PFS) in patients receiving NACT [22]. Randomized trials show a similar PFS and overall survival (OS) in patients undergoing primary or interval CRS. This is despite significantly higher rates of complete gross resection (CGR) or CC-0 resections in the NACT arm. The surgical strategy is to resect only sites of residual disease after NACT which could be responsible for this lack of difference. With a higher CGR or CC-0 the survival with NACT should be longer. Following NACT, a variety of morphological changes take place in tumor nodules. Residual nodules persist or the nodules are replaced by scars or the peritoneum appears absolutely normal. This remains an assumption and till date, no study has compared the visual appearance of tumor before and after NACT. Nevertheless, the high incidence of occult disease in both scar tissue and areas of normal appearing peritoneum, supports this assumption. In another prospective multi-center study, we reported a high incidence of occult disease in 'target regions' like the falciform ligament, umbilical round ligament and the lesser omentum in patients with EOC [23]. It is the failure to address this occult disease that could be responsible for the similar survival between the primary and interval CRS 

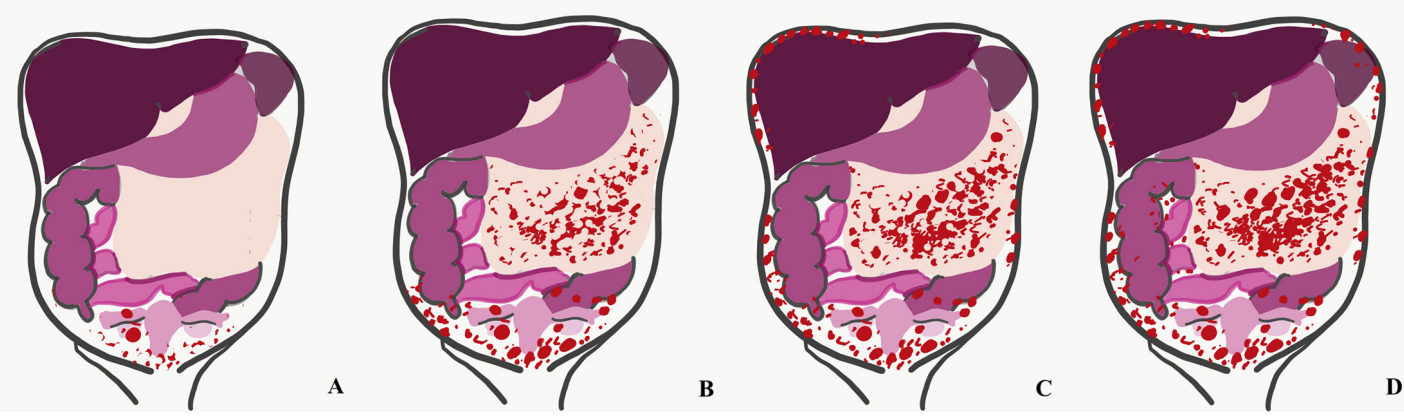

Fig. 1. The redistribution phenomenon and wide spread cancer distribution in ovarian cancer. (A) Involvement of the pelvic peritoneum that occurs early on. (B) The greater omentum and right paracolic gutter are involved next. (C) Involvement of the right hemidiaphragm seen in more advanced disease. (D) Widespread cancer distribution.
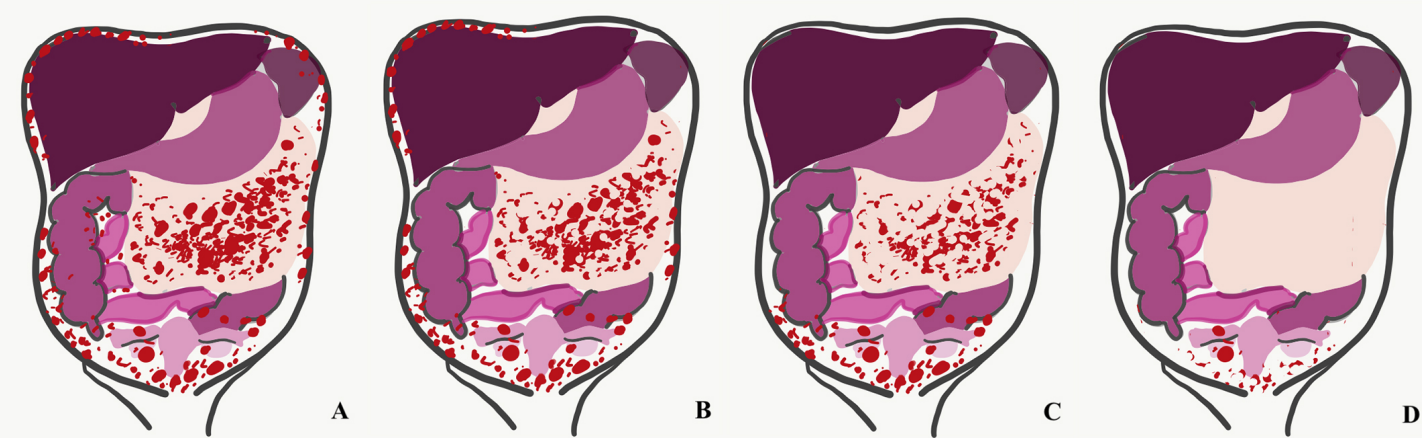

Fig. 2. Sequence of response to chemotherapy in ovarian cancer. (A) Wide spread cancer distribution. (B) The regions involved last like the small bowel mesentery and left diaphragmatic peritoneum respond early. (C) The right upper quadrant is the next area to respond.

(D) The omentum, pelvis and ovaries are the last sites to respond and the most common sites of residual disease.

arms despite a significantly higher rate of $\mathrm{CC}-0$ resections in the interval CRS arms in several randomized trials [24-28].

\subsection{Pattern of response to neoadjuvant chemotherapy}

Given the limitations of both imaging and visual inspection performed during surgery in detecting residual disease following NACT, surgical resections could be guided by the pattern of response to NACT. In our first retrospective study, we demonstrated that the response occurred in a similar sequence or pattern in $95 \%$ of the patients [29]. The small bowel mesentery was the first site to have a complete response, followed by the upper regions, the middle regions, the omentum, the lower regions and lastly the ovaries (Fig. 2). This assessment was based on the pathological evaluation of interval CRS specimens. Subsequently, our prospective study confirmed these findings [30]. In both these studies, we were not able to compare the surgical findings before, during and after NACT and it was assumed that all these regions had disease since only patients with advanced, unresectable disease were treated with NACT and interval CRS.

There are two plausible explanations for this pattern of response. First, the regions in which disease persists longer are those that are rich in lymphatics and it may be difficult to clear the disease completely in these regions compared to those that have a paucity of lymphatics. Second, the regions involved early in course of the disease have a higher tumor burden and could harbor more clones of chemotherapy resistant cells leading to a poorer response compared to regions involved late in the course of peritoneal spread. However, only selected sites, those with the greatest probability of harboring disease were studied and the response at other sites should be studied in future studies.

\subsection{Patterns of recurrence in patients with advanced epithelial ovarian cancer}

When describing the patterns of recurrence, the sites of recurrence after first line therapy and the distribution of recurrent disease in the peritoneal cavity both need to be considered. The pattern of recurrence is influenced by the type of locoregional therapies used.

Seventy-five percent of recurrences in EOC occur in the peritoneum, and in almost $50 \%$ of these cases, the peritoneum is the only site of recurrence [31]. Nodal recurrence is the second most common and is usually associated with peritoneal disease [31].

A retrospective study of 104 patients showed that in comparison to patients receiving systemic chemotherapy (SC) alone, patients who received normothermic intraperi- 
toneal chemotherapy were more likely to recur in the upper abdomen or in extra-abdominal nodes [32].

When HIPEC was added to interval CRS, the incidence of intraperitoneal recurrence was significantly lower than that following CRS alone [33]. In another retrospective multi-center study of 97 patients undergoing interval CRS and HIPEC, systemic sites like the lung, liver and brain were the most common sites of recurrence [34].

Disease can recur in both treated and non-treated areas of the peritoneum. In patients treated with CRS alone, pelvic recurrences are more common than upper abdominal recurrences [35,36]. In our retrospective multi-center study of 60 patients undergoing secondary CRS for recurrent disease, the upper abdomen was the most common site of recurrence $(63.3 \%)$ followed by the pelvis $(55 \%)$. Regional nodes were involved in nearly $50 \%$ of the patients and were a common site of occult disease [37].

Most of the recurrences from ovarian cancer are diffuse [38]. In a study of 270 patients, reported by Ferrandina et al. [39], 'diffuse peritoneal carcinomatosis' was seen in $62.1 \%$ of cases, while recurrences presented as a single lesion or multiple nodules occurred in 9.9 and $26.7 \%$ of cases, respectively. Peritoneal carcinomatosis was defined as 20 or more peritoneal nodules by Chi et al. [38].

\section{Total parietal peritonectomy and wide resection of the visceral peritoneum}

Surgical cytoreduction is the cornerstone of treatment of advanced EOC. The surgical principle which was first propounded by Hoskins was 'to remove as much disease as possible' and the current principle is 'to leave behind no gross residual disease' [40-42]. A meta-analysis published in 2002 that included 6885 patients showed a statistically significant positive correlation between percent maximal cytoreduction and the log median survival time $(p<0.001)$ [42]. Each 10\% increase in maximal cytoreduction was associated with a $5.5 \%$ increase in the median survival time. Over the course of time, surgical proficiency has improved with the introduction of new surgical procedures to aid obtaining a complete cytoreduction $[43,44]$. Gynecological and surgical oncologists treating ovarian cancer are wellversed in performing peritonectomies and upper abdominal surgical procedures like diaphragmatic peritonectomy and resection and clearance of the superior recess of the lesser sac [45-47]. These efforts have resulted in a significant increase in the rates of complete cytoreduction or complete gross resection $[44,48,49]$. Though the OS has improved over time due not just to the progress in surgical therapy but also the introduction of new systemic therapies, recurrence rates remain high and the median OS is only 40-50 months (Table 1) [24-28,43].

EOC is monoclonal in origin (except low grade serous carcinoma which is polyclonal in origin), yet, widespread peritoneal involvement is common and develops early, especially in the case of high-grade serous carcinoma [50].
We hypothesize that just as a CC-0 resection has a survival benefit compared to any amount of residual disease, resecting areas prone to harboring residual disease could add to the survival benefit of a CC- 0 resection.

\subsection{Surgical principles and guidelines for treatment of advanced epithelial ovarian cancer}

Various national and international guidelines recommend that the goal of surgery for advanced EOC should be complete gross resection or no macroscopic residual disease [51-53]. For patients in whom this is not possible, optimal debulking that is residual disease less than $1 \mathrm{~cm}$ in size is recommended. Residual disease less than $1 \mathrm{~cm}$ in size is associated with a longer OS compared to residual disease measuring more than $1 \mathrm{~cm}$ [51]. Peritonectomy procedures and visceral resections are performed to achieve a CGR or optimal debulking [54].

This principle is in contrast to all other solid tumors where surgical resections for early and advanced tumors are defined anatomically and not according to the size of residual disease [55]. For most solid tumors, a wide resection of the primary is performed with a minimum predefined margin (Fig. 3) [55]. This is because there is a high probability of having microscopic disease in the proximity of the tumor. Advanced epithelial ovarian cancer comprises multiple nodules scattered all over the peritoneum. There is no recommendation or consensus on the amount the peritoneum surrounding tumor nodules that should be resected. It is possible that different surgeons resect different amounts of the surrounding peritoneum that harbors occult disease. The parietal peritonectomy that is performed could be termed 'selective parietal peritonectomy' (SPP) in which areas bearing visible disease alone are resected.

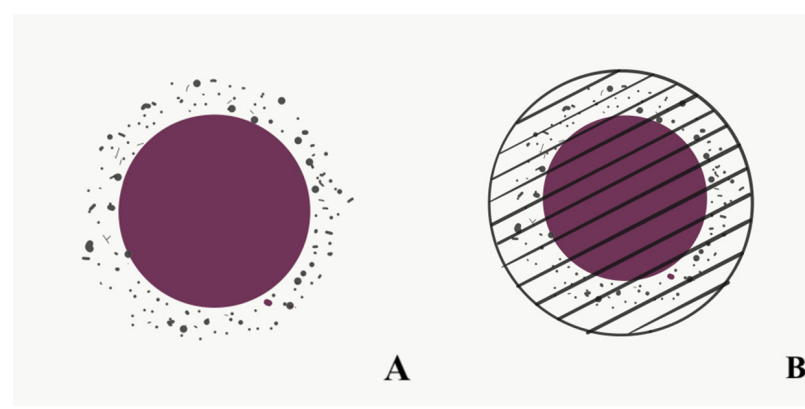

Fig. 3. Principle of surgical resection for solid malignancies. (A) Microscopic disease around tumour nodules. (B) Wide resection of tumour nodules is performed in solid tumours removing a predefined margin of normal tissue on all sides.

In both early and advanced EOC, areas of peritoneum suspicious of harboring disease are excised or biopsied [51]. 'Suspicious' is a very subjective term and there is no morphological description or consensus on what lesions/findings should be considered 'suspicious'. 
Table 1. Progression-free and overall-survival in patients with advanced ovarian cancer undergoing surgery and systemic chemotherapy.

\begin{tabular}{|c|c|c|c|c|c|c|c|}
\hline First author; year [ref] & $\mathrm{N}$ & Trial name & Comparator arms & $\begin{array}{l}\text { Optimal } \\
\text { debulking }\end{array}$ & $\begin{array}{l}\text { CC- } 0 \text { or complete } \\
\text { gross resection }\end{array}$ & $\begin{array}{l}\text { Median progression-free } \\
\text { survival }\end{array}$ & $\begin{array}{c}\text { Median } \\
\text { overall-survival }\end{array}$ \\
\hline Vergote; 2010 [24] & 670 & $\begin{array}{c}\text { EORTC } \\
55971 / \text { NCIC } \\
\text { OV13 }\end{array}$ & PDS versus IDS & $\begin{array}{c}41.6 \%(\mathrm{PDS}) \text { and } \\
80.6 \%(\mathrm{IDS})\end{array}$ & NR & $12 \mathrm{~m}$ in both arms & $29 \mathrm{~m}$ (PDS) and $30 \mathrm{~m}$ (IDS) \\
\hline Kehoe; 2015 [25] & 550 & CHORUS & PDS versus IDS & $\begin{array}{c}28 \%(\text { IIIC) } \\
23 \%(\text { IV })\end{array}$ & $\begin{array}{c}28 \%(\text { IIIC) } \\
30 \%(\text { IV) }\end{array}$ & $107 \mathrm{~m}$ (PDS) and $12 \mathrm{~m}$ (IDS) & $22.6 \mathrm{~m}$ (PDS) and $24.1 \mathrm{~m}$ (IDS) \\
\hline Fagotti; 2020 [26] & 171 & $\begin{array}{c}\text { SCORPION- } \\
\text { NCT01461850) }\end{array}$ & PDS versus IDS & $34.2 \%$ & $61.4 \%$ & $15 \mathrm{~m}$ (PDS) and $14 \mathrm{~m}$ (IDS) & $41 \mathrm{~m}$ (PDS) and $43 \mathrm{~m}$ (IDS) \\
\hline Chi; 2011 [27] & 316 & $\begin{array}{l}\text { Retrospective } \\
\text { study }\end{array}$ & PDS versus IDS & $\begin{array}{l}24 \%(\mathrm{PDS}) \\
54 \%(\mathrm{IDS})\end{array}$ & $\begin{array}{l}71 \%(\mathrm{PDS}) \\
86 \%(\mathrm{IDS})\end{array}$ & $13 \mathrm{~m}$ (IDS) and $17 \mathrm{~m}$ (PDS) & $37 \mathrm{~m}$ (IDS) and $50 \mathrm{~m}$ (PDS) \\
\hline Ru-Hain; 2012 [28] & 242 & $\begin{array}{l}\text { Retrospective } \\
\text { study }\end{array}$ & PDS versus IDS & NR & $\begin{array}{c}7.5 \%(\mathrm{PDS}) \text { and } \\
27 \%(\mathrm{IDS})\end{array}$ & $11 \mathrm{~m}$ (PDS) and $14 \mathrm{~m}$ (IDS) & $29 \mathrm{~m}$ (PDS) and $33 \mathrm{~m}$ (IDS) \\
\hline
\end{tabular}

Abbreviations: NR, not reported; PDS, primary debulking surgery; IDS, interval debulking surgery; m, months.

The other problem with ovarian cancer is the relatively low accuracy of all imaging modalities in determining the extent of disease accurately. Even with a peritoneal MRI for staging, the accuracy ranges between 15-70\% [56,57]. Whereas imaging may be able to predict inoperability more accurately it is the inability to detect small nodules that if not looked for may be missed on surgical exploration and lead to recurrence, that is more problematic. Thus, the extent of surgery performed in advanced EOC is largely dependent on the extent of exploration performed and the surgeon's evaluation of the peritoneal lesions and it is only plausible to assume that there is a lot of variation in the extent of surgery that is performed for a similar amount or extent of disease (Fig. 4). This statement is borne out by the large differences in operative times for the same disease stages reported in different surgical studies [24-28].

\subsection{Alternative surgical strategy for advanced EOC}

Based on the above data, resecting visible disease alone, that is performing a selective parietal peritonectomy (SPP) especially after NACT may not be sufficient in EOC. Complete removal of the parietal peritoneum (i.e., a total parietal peritonectomy [TPP]) has shown a survival benefit in primary peritoneal serous carcinoma (PPSC) and peritoneal mesothelioma and may have a role EOC [58,59]. EOC is monoclonal in origin compared to PPSC which is polyclonal. The monoclonal origin does not support the rationale for performing a TPP $[50,58,59]$. The preponderance of disease in the parietal peritoneum which constitutes only $20 \%$ of the peritoneal surface area but harbours $80 \%$ of the tumour deposits is another point that favours the rationale for performing a TPP $[12,17]$.

\subsection{Total parietal peritonectomy in treatment armamentarium of advanced ovarian cancer}

A total parietal peritonectomy irrespective of the extent of parietal peritoneal involvement can be performed

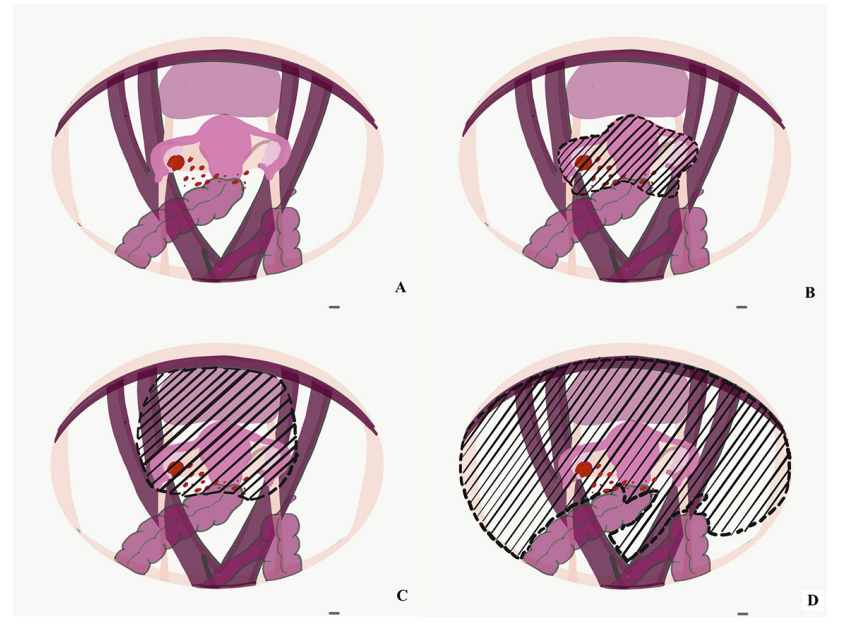

Fig. 4. Variation in the amount of peritoneum resected by different surgeons for the same amount of peritoneal disease. (A) Disease in the pelvic peritoneum. (B) Limited resection of the surrounding peritoneum. (C) More extensive peritoneal resection compared to that in B. (D) Complete removal of the pelvic peritoneum.

during primary or interval CRS. The peritoneum is the first line of defence and removing normal peritoneum may have its own risks [60]. However, the normal peritoneum in ovarian cancer may not be normal but 'normal appearing' given the high incidence of occult disease. Second, such resections are only performed in patients whom a $\mathrm{CC}-0 / 1$ resection can be obtained.

In our retrospective multi-center study of 79 patients comparing TPP and SPP, 30 patients had a TPP. The 90day grade 3-4 morbidity (23.3\% for TPP, $14.2 \%$ for SPP, $p$ $=0.58)$ the 90 -day post-operative mortality was similar $(p$ $=0.58$ ) between the two groups [61].

The 3-year OS was $95 \%$ for TPP and $70.8 \%$ for SPP $(p=0.06)$. The only independent predictor of OS was grade 
3-4 morbidity $(p=0.01)$. Microscopic residual disease was seen in $23.3 \%$ with normal looking peritoneum in TPP group. Due to the retrospective nature of this study and its heterogeneous patient population, no conclusions regarding survival benefit could be drawn. But the 3-year OS of $95 \%$ in the TPP group is an important finding [61].

We are conducting a prospective, single arm, multicentre study evaluating the role of TPP during interval CRS. Interval CRS after NACT at the 3 centres participating in this study is only performed for patients in whom the disease is unresectable as determined on preoperative evaluation that includes a staging laparoscopy. The entire parietal peritoneum is invariably involved in these patients and thus, TPP is performed to remove the peritoneum that was involved prior to NACT. This study, the TORPEDO (total removal of the peritoneum at interval debulking for ovarian cancer) study is registered with the clinical trials registry of India (CTRI/2018/12/016789). There is a fixed surgical protocol that defines the boundaries of each peritonectomy to be performed. In addition to the parietal peritonectomies (pelvic, bilateral anteroparietal, right and left upper quadrant), a greater and lesser omentectomy is performed for all patients [20]. For mesenteric disease, resection of the involved peritoneum is performed. Complete mesenteric peritonectomy is not part of the protocol. The small bowel mesenteric peritoneum is biopsied in 4 quadrants in absence of visible disease. In addition to a TPP, wide resection of the visceral peritoneum preserving the underlying viscera whenever possible, is performed in areas prone to harbouring disease. For example, the omental attachment on the right colon and the reflection of the peritoneum from the paracolic gutter onto the mesocolon are common sites of disease and are removed (Fig. 5) [20]. Similarly, the reflection of the greater omentum on the posterior wall of the stomach that forms a boundary of the lesser sac is removed. We have a low threshold to resect the rectosigmoid colon as it is involved early in the course of disease and the probability of microscopic disease is high (Fig. 6).

As we have described previously, most of these patients do not require a diverting o'stomy and the incidence of anastomotic leaks is very low [20]. This surgery requires patient and meticulous exploration of the abdominal cavity, lysis of all adhesions, and complete mobilization of the lobes of the liver to identify all sites of residual disease and scarring. In addition to the surgical protocol there is protocol for evaluation of CRS specimens that is followed at all participating centres.

For primary CRS, the evidence is even more scarce. There is only one prospective study of 16 patients that reported the safety and feasibility of TPP during primary CRS [62]. The morbidity was higher than other reports. However, the authors did not report on the incidence of occult disease. No other prospective or retrospective study has evaluated the role of TPP in the setting of primary CRS.

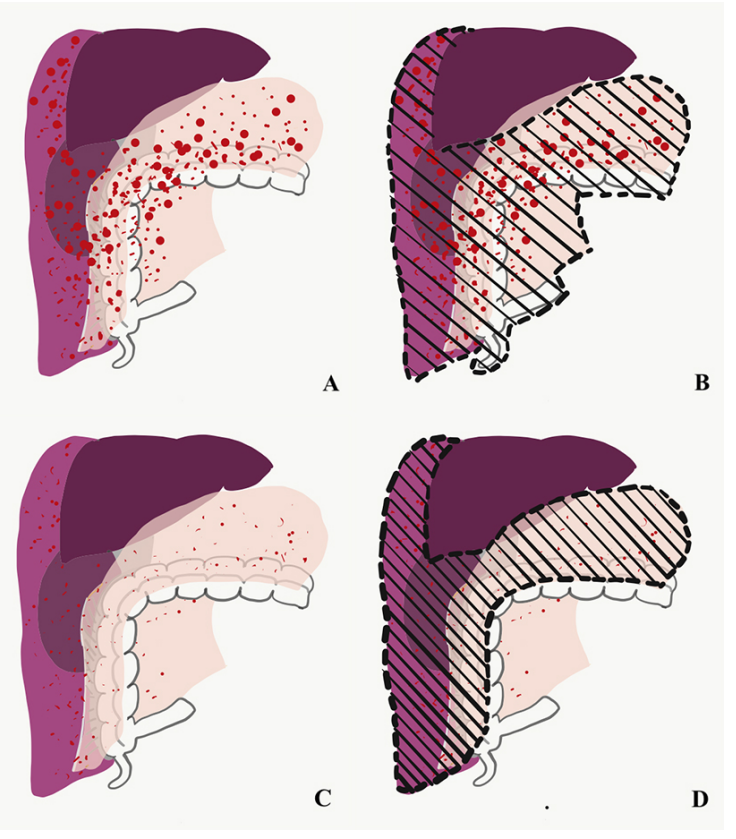

Fig. 5. Wide resection of the visceral peritoneum around the right colon. (A) Extensive involvement of the greater omentum, right paracolic gutter and right upper quadrant peritoneum. (B) A right hemicolectomy is need to completely resect all the tumour nodules. (C) Reduction in the tumour burden following a response to chemotherapy. (D) The omental attachment on the right colon is dissected off and the peritoneum overlying the colonic mesentery resected to obtain a complete cytoreduction in the region without performing a right hemicolectomy.

\subsection{Proof-of-principle for performing TPP during interval CRS}

An analysis of the pathological findings in the first 50 patients enrolled in the TORPEDO study provide the proof-of-principle for performing a TPP [20]. There are two points of concern- the performance of visual inspection and the distribution of occult disease. When the parietal peritoneum alone is removed preserving a large portion of the visceral peritoneum, the accuracy of visual inspection should be lower for the parietal regions and the incidence of occult disease higher in these regions [7].

To demonstrate the accuracy of visual inspection, the surgical and pathological findings were compared in each of the 13 regions of the PCI. The sensitivity $(p=0.103)$ and specificity $(p<0.001)$ of visual inspection in detecting residual disease were significantly lower for the parietal regions (regions 0-8) compared to the small bowel regions (regions 9-12 representing the visceral peritoneum) (Table 2, Ref. [20]). The false negative were significantly higher for the parietal peritoneal regions $(p<0.001)$. When lesions scores $0-1$ were considered, the sensitivity was significantly lower for the parietal regions compared to the visceral regions $(p=0.014)$ (Table 3) [20]. 


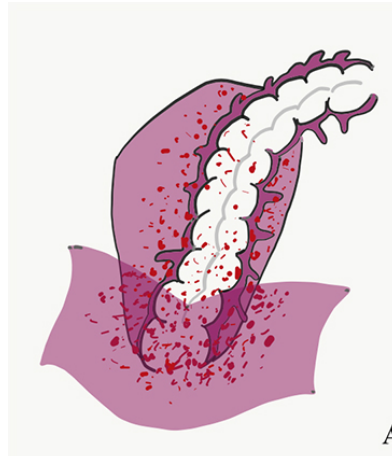

$\mathbf{A}$

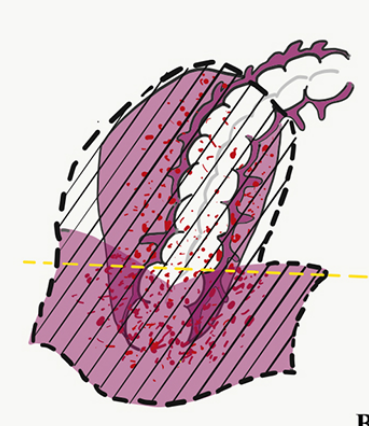

B

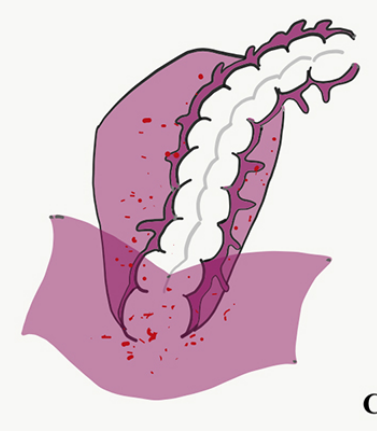

C

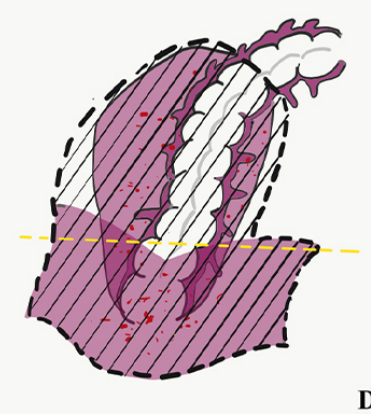

Fig. 6. Disease spread over and around the rectosigmoid in advanced ovarian cancer. (A) Extensive disease over the rectosigmoid colon. (B) Anterior resection is performed preserving the mid-rectum where the peritoneum is loosely attached and can be stripped off the rectum. (C) Reduction in the disease burden following a response to systemic chemotherapy. (D) Rectal resection is performed in the same manner as in B to clear all the disease from the recto-sigmoid mesentery.

Similarly, the incidence of both overt $(p<0.001)$ and occult $(p<0.001)$ disease was higher in the parietal regions compared to the small bowel regions representing the visceral peritoneum which supports the rationale of performing a TPP during interval CRS.

\subsection{Morbidity}

One major concern with performing more extensive surgery is the morbidity, its impact on the quality of life and the delay in starting adjuvant chemotherapy [20]. In the above study, 90 -day grade 4-3 morbidity was $22 \%$ and the 90 -day post-operative mortality $2 \%$ which could both be considered acceptable [20]. 6\% required a surgical intervention for the complications. The most common complication was intra-abdominal fluid collection that required aspiration in $10 \%$ of the patients. All these patients were managed with a radiologic intervention alone performed on an out-patient basis. No bowel fistulas or perforations occurred. All patients were able to start chemotherapy within 6 weeks of surgery.

In another study of 144 patients we studied the major morbidity in patients undergoing TPP in the primary interval and recurrent settings [63]. Thirty (20.8\%) patients had primary cytoreductive surgery (CRS), $90(62.5 \%)$ interval CRS and 24 (16.2\%) CRS for recurrence. HIPEC was performed in 57 (39.5\%) patients. 93.7\% had all 7 peritonectomies, $61 \%$ had more than three visceral resections and $62.5 \%$ had at least one bowel anastomosis. All patients had intermediate or complex surgery according to the surgical complexity score (SCS) by Aletti et al. [64] 80\% had a complex surgery. Grade 3-4 morbidity was seen in $31.9 \%$ and was similar with/without HIPEC. In this study a large proportion of patients had all 7 peritonectomies (93.7\%) and multi-visceral resections ( $>3$ in $61 \%$ ) and this is why both the number of peritonectomies and visceral resections did not have an impact on the morbidity. On multi-variable logistic regression analysis, patients receiving NACT $(p=$ $0.031)$ and undergoing small bowel resection $(p=0.038)$ had a higher risk of grade 3-4 morbidity and those with peritoneal cancer index $(\mathrm{PCI})<10(p=0.001)$ had a lower risk. Small bowel resection was performed in 10 patients of which $9 / 10$ had a PCI $>10$ and $8 / 10$ patients had both 2 or more bowel anastomoses and resection of more than 3 viscera. Thus, small bowel resection could be considered a surrogate for more extensive surgery in this study and it was an independent predictor of an increased major morbidity. HIPEC had no impact on the morbidity. The number of bowel anastomoses ( $>1$ in $15.2 \%$ and at least 1 in $62.3 \%$ ) was not an independent predictor of increased major morbidity either. All except two patients started chemotherapy within 6 weeks of surgery. Thus, the morbidity of TPP with or without HIPEC could be considered acceptable for advanced EOC.

\subsection{Impact of TPP on recurrence and survival}

The impact of TPP on PFS and OS needs to be demonstrated to conclusively establish its role in the treatment of EOC during interval CRS. Our retrospective study had many limitations due to which it is not possible derive conclusions on survival from that study [56]. There is one other retrospective study that compared outcomes in patients undergoing TPP and SPP but the study had methodological problems as the criteria for performing a TPP and SPP were not specified [65]. The data from our prospective study are not mature. We considered an important endpoint that is not usually evaluated in clinical trials- recurrence within 6 months of therapy or platinum resistant recurrence (PRR). Patients with PRR have a poorer survival and lower response rates to second line therapies. In this study of 70 patients, PRR was seen in $7.1 \%$ which represents an $80 \%$ reduction from what has been reported previously [66]. Though the most common site of recurrence was the visceral peritoneum $(\mathrm{N}=9)$, seven $(>40 \%)$ patients did not develop recurrence in the visceral peritoneum (Table 4, Ref. [66]). The morbidity, mortality and the incidence and distribution of occult disease were similar to our previous reports. 
Table 2. Incidence of involvement of different peritoneal regions (according to Sugarbaker's peritoneal cancer index) in absence of visible disease in 50 patients undergoing interval cytoreductive surgery (adapted from ref 20 with permission [20]).

\begin{tabular}{|c|c|c|c|c|}
\hline \multirow{2}{*}{ Peritoneal region } & \multirow{2}{*}{$\begin{array}{c}\text { Dissection performed } \\
\mathrm{N}(\%)\end{array}$} & \multicolumn{2}{|c|}{ Total number in which it was involved Incidence of occult disease* } & \multirow{2}{*}{$\begin{array}{c}\text { Incidence of occult } \\
\text { disease in involved regions }\end{array}$} \\
\hline & & $\mathrm{N}(\%)$ & $\mathrm{N}(\%)$ & \\
\hline \multicolumn{5}{|c|}{ Parietal peritoneal regions $(0-8)$} \\
\hline 1 & $50(100.0)$ & $33(66.0)$ & $1(2.0)$ & $1(3.0)$ \\
\hline 2 & $50(100.0)$ & $27(54.0)$ & $5(10.0)$ & $5(18.5)$ \\
\hline 3 & $50(100.0)$ & $22(44.0)$ & $2(4.0)$ & $2(9.0)$ \\
\hline 4 & $50(100.0)$ & $22(44.0)$ & $5(10.0)$ & $5(22.7)$ \\
\hline 5 & $50(100.0)$ & $31(62.0)$ & $1(2.0)$ & $1(3.2)$ \\
\hline 6 & $50(100.0)$ & $43(86.0)$ & $3(6.0)$ & $3(6.9)$ \\
\hline 7 & $50(100.0)$ & $31(62.0)$ & $2(4.0)$ & $2(6.4)$ \\
\hline 8 & $50(100.0)$ & $21(42.0)$ & $7(14.0)$ & $7(33.3)$ \\
\hline Total no of regions & $450(100.0)$ & $271(60.2)$ & $32(7.1)$ & $32(11.8)$ \\
\hline \multicolumn{5}{|c|}{ Small bowel regions $(9-12)$} \\
\hline 10 & $50(100.0)$ & $2(4.0)$ & $1(2.0)$ & $1(50.0)$ \\
\hline 11 & $50(100.0)$ & $9(18.0)$ & $0(0.0)$ & $0(0.0)$ \\
\hline 12 & $50(100.0)$ & $11(22.0)$ & $0(0.0)$ & $0(0.0)$ \\
\hline Total number of regions & $200(100.0)$ & $28(14.0)$ & $1(0.5)$ & $1(3.5)$ \\
\hline All regions & $650(100.0)$ & $299(46.0)$ & $33(5.0)$ & $33(11.0)$ \\
\hline \multicolumn{2}{|c|}{$\begin{array}{l}p \text {-value } \\
\text { (for the comparison between parietal and small bowel regions) }\end{array}$} & $<0.001$ & $<0.001$ & 0.185 \\
\hline
\end{tabular}

*Occult disease refers to presence of disease on pathological examination when visual inspection is negative.

\subsection{Impact of response to neoadjuvant chemotherapy}

NACT produces a pathological complete or nearcomplete response in the peritoneum in around $15 \%$ of the patients [67]. In most cases, ovaries still harbour residual disease. Currently, there is no accurate method of predicting a complete response preoperatively [68]. Intraoperatively as well, it is difficult to accurately identify patients with a complete response. In other tumours, like rectal cancer, where the tumour is confined to one region of the abdominal cavity, predicting a pathological complete response is difficult and most patients require a surgical resection [69]. More number of patients and studying patterns of response in more detail with a correlation with the clinical and radiological findings is needed to see if there are subgroups in which a TPP could be omitted.

\subsection{Regional lymph node involvement}

Regional lymph node involvement can be secondary to the primary tumour or the peritoneal metastases [70]. Extensive pelvic peritoneal disease increases the risk of pelvic lymph node involvement. The impact of increasing tumour burden on nodal positivity has been demonstrated in one retrospective study [71]. Apart from the pelvic and para-aortic nodes, there are upper abdominal nodes like those around the porta, celiac axis, para-cardiac and sub-xiphoid nodes that can be involved secondary to peritoneal disease. Nodes in the small and large bowel mesentery can be involved secondary to bowel involvement by peritoneal deposits.
In one retrospective study, the incidence of mesorectal node involvement was correlated with the depth of rectal wall infiltration. Even in those with serosal involvement, nearly $10 \%$ had positive mesorectal nodes, and it was more than $40 \%$ in those with full-thickness involvement [71].

The LION trial does not recommend performing lymphadenectomy for 'normal appearing' nodes [72]. However, in our prospective study regional nodes have been a common site of failure (17.1\% of all patients and $70.5 \%$ of patients with recurrence disease) [66]. When a more aggressive approach like TPP is employed, it is only prudent to be aggressive in dealing with the regional nodes as well. Whilst pelvic node dissection carries little morbidity, paraaortic lymphadenctomy carries a greater risk of complications. In our study, the main problem was postoperative fluid collections that required multiple aspirations [66]. The Careful mapping of other regional nodes that are involved secondary to peritoneal disease on imaging and during surgery should be performed and suspicious and/or metastatic nodes are resected. The extent of lymphadenectomy that should be performed with a TPP is another areas that requires evaluation in future studies.

\subsection{Clinical end-points for randomized trials/prospective studies evaluating the role of TPP}

TPP is a surgical therapy and it is assumed that it should provide better locoregional control. There is no consensus on what should be an ideal end-point to demonstrate the clinical benefit of locoregional therapies in EOC. Bet- 
Table 3. Comparison of the performance of visual inspection in predicting the presence or absence of disease in the parietal and visceral regions in 50 patients undergoing interval cytoreductive surgery (adapted from ref 20 with permission [20]).

\begin{tabular}{|c|c|c|c|c|c|c|c|c|}
\hline \multirow{2}{*}{ Parameter } & \multicolumn{2}{|c|}{ Parietal regions $(0-8)$ Small bowel regions $(9-12)$} & \multirow{2}{*}{$p$-value } & \multirow{2}{*}{$\begin{array}{c}\text { Gall bladder } \\
\mathrm{N}(\%)\end{array}$} & \multirow{2}{*}{$\frac{\text { Rectum }}{\mathrm{N}(\%)}$} & \multirow{2}{*}{$\begin{array}{l}\text { Spleen } \\
\mathrm{N}(\%)\end{array}$} & \multirow{2}{*}{$\begin{array}{c}\text { Appendix } \\
\mathrm{N}(\%)\end{array}$} & \multirow{2}{*}{$\begin{array}{c}\text { Right colon } \\
\mathrm{N}(\%)\end{array}$} \\
\hline & $\mathrm{N}(\%)$ & $\mathrm{N}(\%)$ & & & & & & \\
\hline Number dissected & $450(100.0)$ & $200(100.0)$ & - & $50(100.0)$ & $35(70.0)$ & $23(46.0)$ & $18(36.0)$ & $8(16.0)$ \\
\hline False negative & $32(7.1)$ & $2(1.0)$ & 0.001 & $0(0.0)$ & $0(0.0)$ & $0(0.0)$ & $0(0.0)$ & $0(0.0)$ \\
\hline False positive & $94(21.5)$ & $39(19.5)$ & 0.685 & $3(6.0)$ & $2(5.7)$ & $2(8.6)$ & $5(27.7)$ & $1(12.5)$ \\
\hline True negative & $88(19.5)$ & $127(63.5)$ & $<0.001$ & $36(72.0)$ & $0(0.0)$ & $0(0.0)$ & $0(0.0)$ & $0(0.0)$ \\
\hline True positive & $236(52.4)$ & $32(16.0)$ & $<0.001$ & $11(22.0)$ & $33(94.3)$ & $21(91.4)$ & $13(72.3)$ & $7(87.5)$ \\
\hline Sensitivity & $88.0 \%$ & $94.1 \%$ & 0.103 & $100 \%$ & NA & NA & NA & NA \\
\hline Specificity & $48.3 \%$ & $76.5 \%$ & $<0.001$ & $92.3 \%$ & NA & NA & NA & NA \\
\hline Number dissected (R) & $208(46.2)$ & $170(85.0)$ & $<0.001$ & - & - & - & - & - \\
\hline False negative & $26(12.5)$ & $2(1.1)$ & $<0.001$ & - & - & - & - & - \\
\hline False positive (R) & $48(23.0)$ & $26(15.2)$ & 0.144 & - & - & - & - & - \\
\hline True negative & $88(42.3)$ & $127(74.7)$ & $<0.001$ & - & - & - & - & - \\
\hline True positive (R) & $46(22.1)$ & $15(8.8)$ & $<0.001$ & - & - & - & - & - \\
\hline Sensitivity (R) & $63.8 \%$ & $88.2 \%$ & 0.014 & - & - & - & - & - \\
\hline Specificity (R) & $64.7 \%$ & $83.0 \%$ & $<0.001$ & - & - & - & - & - \\
\hline
\end{tabular}

Abbreviations: R, restricted value (after excluding regions with lesion scores 2 and 3); NA, not applicable.

ter loco-regional control should increase the OS especially in EOC where a delay in recurrence leads to a delay in second-line therapy, a longer platin-free interval and therefore, presumably, a better response to second-line therapies [73]. Peritoneal metastases (PM) lead to ascites and bowel obstruction and bring down the quality of life. For PM of digestive origin, it has been proposed that obstruction-free survival could be a useful end-point to demonstrate the benefit of HIPEC [74]. Our retrospective study showed that the visceral peritoneum was not a site of recurrence in $42 \%$ of the patients who developed recurrence/progression [34]. Thus, theoretically, TPP should not just prolong PFS but OS as well.

In addition to locoregional therapies, the time to recurrence is influenced by another factor that is the response to chemotherapy. Bohm et al. [67] demonstrated a 50\% longer PFS in patients with complete or near complete response to chemotherapy compared to the moderate and poor responders. The difference in OS between the different responders was less compared to the difference in PFS between these groups. Locoregional therapies should have a greater impact on OS compared to the response to chemotherapy during first-line therapy by reducing the burden of chemotherapy resistant cells and thus enhancing the response to subsequent therapies. Thus, not just PFS but OS should be considered an important end-point while evaluating the role of TPP. A recent meta-analysis of 17 unique randomized trials of standard, consolidation, and maintenance systemic therapies or targeted therapies with data from 11029 unique patients did not establish PFS as a surrogate end point for OS in first-line treatment of advanced EOC and the authors recommended that when PFS is the primary end-point, OS should be a secondary end point [75].

\section{HIPEC}

\subsection{Rationale and pitfalls of HIPEC}

HIPEC involves the circulation of a heated chemotherapy solution in the peritoneal cavity for 30-120 minutes using a roller pump and heat exchanger (now custom made machines). The direct instillation of chemotherapy into the peritoneal cavity has many theoretical benefit like direct exposure of the tumor cells to the drug, a decreased systemic absorption which allows a prolonged exposure of the tissues to the drug and a reduced systemic absorption thus, allowing larger doses to be administered [76,77]. Intraperitoneally administered drugs can gain access to the subperitoneal lymphatics and act on trans-lymphatic tumor dissemination. Through the sub-peritoneal lymphatic network, drugs reach different areas of the subperitoneal space even when the mechanical distribution is uneven [78,79].

Despite this pharmacokinetic advantage, the depth of penetration of the chemotherapeutic drug into the peritoneum and tumor nodules is not more than $2-3 \mathrm{~mm}$ and HIPEC acts best in the presence of minimal or no residual disease [80,81]. HIPEC performed following a complete CRS acts on free intraperitoneal cancer cells and reduces the implantation of these cells at the surgical site [82].

The are many theoretical benefits of hyperthermia but the clinical benefit has not been proven for the treatment of PM. Heat itself is cytotoxic, it potentiates the cytotoxicity of the chemotherapeutic drugs and in some instances, helps in overcoming drug resistance [83,84].

\subsection{Current evidence on the benefit of HIPEC}

\subsubsection{Primary CRS/debulking}

Most of the preliminary evidence on HIPEC in addition to primary CRS comes from retrospective studies (the majority having less than 100 patients) which showed that 
Table 4. Sites and timing of recurrence/disease progression in 17 patients* of the 70 patients undergoing interval cytoreductive surgery (adapted from ref. 66 with permission [66]).

\begin{tabular}{|c|c|c|c|c|c|c|c|c|c|}
\hline \multirow{2}{*}{ Patient } & \multicolumn{8}{|c|}{ Sites of recurrence } & \multirow{2}{*}{$\begin{array}{l}\text { Time to } \\
\text { recurrence } \\
\text { (Months) }\end{array}$} \\
\hline & $\begin{array}{c}\text { Mediastinal } \\
\text { nodes }\end{array}$ & Pleura & $\begin{array}{c}\text { Infra-renal } \\
\text { retroperitoneal nodes }\end{array}$ & $\begin{array}{c}\text { Suprarenal } \\
\text { retroperitoneal nodes }\end{array}$ & $\begin{array}{c}\text { Retroperitoneal } \\
\text { soft tissue }\end{array}$ & $\begin{array}{c}\text { Visceral } \\
\text { peritoneum }\end{array}$ & $\begin{array}{c}\text { Small bowel } \\
\text { mesentery }\end{array}$ & $\begin{array}{c}\text { Parenchymal } \\
\text { liver metastases }\end{array}$ & \\
\hline 1 & + & & & & & & & & 12 \\
\hline 2 & + & + & + & & + & + & + & & 12 \\
\hline 3 & + & + & + & & & + & + & & 16 \\
\hline 4 & & & + & + & + & & & & 11 \\
\hline 5 & & & & + & & + & & & 15 \\
\hline 6 & & + & & & & & & & 2 \\
\hline 7 & & & & + & & + & & & 15 \\
\hline 8 & & & & & & & & + & 9 \\
\hline 9 & & & & + & & + & & & 3 \\
\hline 10 & & & & + & & + & & & 12 \\
\hline 11 & & & & & & & & & 13 \\
\hline 12 & & & + & + & & + & + & & 6 \\
\hline 13 & & & + & & & + & & & 13 \\
\hline 14 & + & & & & & & & & 8 \\
\hline 15 & & & & + & & + & & & 18 \\
\hline 16 & & & + & + & & & & & 17 \\
\hline 17 & & & & & & & + & & 3 \\
\hline & 4 & 3 & 6 & 8 & 2 & 9 & 4 & 1 & \\
\hline
\end{tabular}

*The sites involved at the first detection of recurrence/progression on imaging have been considered.

the morbidity of HIPEC in addition to CRS was acceptable [2]. The study population included patients undergoing CRS-HIPEC at different time points in the history of EOC, the time period spanned several years, and the treatment protocols even within the small groups were heterogeneous. The selection criteria were not clearly defined, and several series comprised patients with extensive disease that were referred to specialized units after having undergone unsuccessful prior surgical attempts [2].

Chiva et al. [85] published a systematic review that included 11 studies comprising 248 patients in which there was no benefit of adding HIPEC to primary CRS. Contrary to this, two systematic reviews and meta-analyses reported improved outcomes with HIPEC in addition to CRS. Huo et al. [86] performed a meta-analysis of 9 comparative and 28 non-comparative studies evaluating the role of HIPEC for primary and recurrent EOC. In the primary setting, the meta-analysis performed on patients of 3 studies showed a survival benefit with HIPEC at 2, 3, 4, 5 and 8 years. These studies included patients with Stage II-III-B as well and did not make a distinction between patients undergoing primary and interval CRS. In a subgroup analysis of patients with stage III-C and IV alone, the hazard ratio (HR) for OS was $3.61(95 \% \mathrm{CI}: 1.55-8.37 ; p=0.003)$ and for OS at 5 years 2.25 (95\% CI: $1.07-4.71 ; p=0.030)$ both favouring the use of HIPEC [86]. Zhang et al. [87] performed a similar meta-analysis and demonstrated a benefit of HIPEC for all patients undergoing primary or interval $\mathrm{CRS}(\mathrm{HR}=0.59$, 95\% CI: 0.46 to 0.75 for OS and HR $=0.41,95 \% \mathrm{CI}: 0.32$ to 0.54 for PFS) as well as those with stage III or IV disease
$(\mathrm{HR}=0.64,95 \% \mathrm{CI}: 0.50$ to 0.82 for $\mathrm{OS}$ and $\mathrm{HR}=0.36$, $95 \%$ CI: 0.20 to 0.65 for PFS).

Lei et al. [88] reported a retrospective propensity score-matched study including patients with EOC undergoing primary CRS with $(\mathrm{N}=425)$ or without HIPEC (N =159) [55]. HIPEC was performed with $50 \mathrm{mg} / \mathrm{m}^{2}$ of Cisplatin on days 1,3 , and 5 , which is not the common practice.

At a median follow-up of 42.2 months, the addition of HIPEC led to a nearly 16-month increase in OS (median OS, $49.8 \mathrm{~m}$; 95\% CI, 45.2-60.2 m for CRS-HIPEC versus $34.0 \mathrm{~m} ; 95 \% \mathrm{CI}, 28.9-42.3$ months for CRS alone). The iterative HIPEC was associated with a $36 \%$ reduction in the risk of death [PS weighted HR, 0.64; 95\% CI, 0.50-0.82; $p$ $<0.001]$ without a significant increase in severe surgical complications and systemic toxicities. All the limitations of a randomized study and a retrospective analysis apply to this study.

In the only RCT reported so far, Lim et al. [89] reported no benefit of the addition of HIPEC to primary CRS. One-hundred-eighty-four patients undergoing both primary and interval CRS were randomized to HIPEC or no HIPEC. Though the trial has been completed, the final results have not been reported or published. The small sample size, the inclusion or patients undergoing both primary and interval CRS and performing HIPEC for patients with optimal debulking (residual disease $<1 \mathrm{~cm}$ ) are some of the limitations of this trial.

There are four RCTs in progress looking at the role of HIPEC in addition to primary CRS (Table 5, Ref. [5,56]): The OVIHIPEC-2 trial in Europe, Australia and the 
Table 5. Published and ongoing clinical trials on the role of HIPEC in advanced ovarian cancer.

\begin{tabular}{|c|c|c|c|c|c|c|}
\hline ClinicalTrials.gov ID & $\begin{array}{l}\text { Phase; primary } \\
\text { institution/group }\end{array}$ & Indication & HIPEC regimen (s) & Control arm & Experimental arm & Main outcomes \\
\hline Van Driel [5] & $\begin{array}{l}\text { Phase } 3 \text { randomized } \\
\text { controlled trial; } \\
\text { Netherlands Cancer } \\
\text { Institute }\end{array}$ & $\begin{array}{l}\text { Advanced ovarian cancer } \\
\quad \text { (interval surgery) }\end{array}$ & $\begin{array}{l}\text { Cisplatin } 100 \mathrm{mg} / \mathrm{m}^{2} \text { for } \\
90 \mathrm{mins}\end{array}$ & $\mathrm{CRS}+\mathrm{SC}$ & $\mathrm{CRS}+\mathrm{HIPEC}+\mathrm{SC}$ & $\begin{array}{c}\text { Benefit in the HIPEC arm } \\
\text { in PFS and OS; Same } \\
\text { morbidity }\end{array}$ \\
\hline $\operatorname{Lim}[56]$ & $\begin{array}{l}\text { Phase } 3 \text { randomized } \\
\text { controlled trial; National } \\
\text { Cancer Centre, Korea }\end{array}$ & $\begin{array}{l}\text { Advanced ovarian cancer } \\
\text { (primary and interval } \\
\text { surgery) }\end{array}$ & $\begin{array}{c}\text { Cisplatin } 75 \mathrm{mg} / \mathrm{m}^{2} \text { for } 90 \\
\text { mins }\end{array}$ & CRS + SC (92) & CRS + HIPEC + SC (92) & $\begin{array}{l}\text { No benefit of HIPEC in } \\
\text { the PDS arm; benefit with } \\
\text { HIPEC in PFS and OS } \\
\text { after } 20 \text { months of follow } \\
\text { up in the IDS arm }\end{array}$ \\
\hline \multicolumn{7}{|c|}{ Only abstract; full results not available } \\
\hline NCT03842982 (CHIPPI) & $\begin{array}{l}\text { Randomized Phase III; } \\
\text { Centre Oscar Lambert }\end{array}$ & $\begin{array}{c}\text { Advanced ovarian, } \mathrm{FT} \text { and } \\
\text { PP cancer }\end{array}$ & $\begin{array}{c}\text { Cisplatin } 100 \mathrm{mg} / \mathrm{m}^{2} \text { for } \\
90 \mathrm{mins}\end{array}$ & $\mathrm{PDS} / \mathrm{IDS}+\mathrm{SC}$ & PDS/IDS + HIPEC + SC & \\
\hline NCT02349958 & $\begin{array}{l}\text { Non randomized; Bay } \\
\text { Area Gynecology } \\
\text { Oncology, US }\end{array}$ & $\begin{array}{l}\text { Advanced ovarian cancer; } \\
\text { other primary sites }\end{array}$ & Various regimens & & $\mathrm{CRS}+\mathrm{HIPEC}+\mathrm{SC}$ & \\
\hline NCT02124421 (HOT trial) & $\begin{array}{l}\text { Mercy Medical Center, } \\
\text { US }\end{array}$ & Advanced ovarian cancer & $\begin{array}{c}\text { Carboplatin (AUC 6) for } \\
90 \mathrm{mins}\end{array}$ & $\mathrm{CRS}+\mathrm{SC}+\mathrm{IPC}$ & $\mathrm{CRS}+\mathrm{HIPEC}+\mathrm{SC}$ & \\
\hline NCT01970722 & $\begin{array}{c}\text { City of Hope Medical } \\
\text { Center, UC }\end{array}$ & $\begin{array}{l}\text { Advanced ovarian, } \mathrm{FT} \text {, } \\
\text { uterine and PP cancer }\end{array}$ & Various regimens & & $\mathrm{CRS}+\mathrm{HIPEC}+\mathrm{SC}+\mathrm{IPC}$ & \\
\hline \multirow[t]{2}{*}{ NCT02567253 (OvIP1) } & $\begin{array}{l}\text { Quadruple arm, Phase II; } \\
\text { University Hospital, } \\
\text { Ghent, Belgium }\end{array}$ & Advanced ovarian cancer & $\begin{array}{c}\text { Cisplatin } 75 \mathrm{mg} / \mathrm{m}^{2} \mathrm{NT} \text { or } \\
\text { HT for } 90 \mathrm{mins}\end{array}$ & & $\mathrm{CRS}+\mathrm{HIPEC}+\mathrm{SC}$ & \\
\hline & & & $\begin{array}{l}\text { Cisplatin } 100 \mathrm{mg} / \mathrm{m}^{2} \mathrm{NT} \\
\text { or HT for } 90 \mathrm{mins}\end{array}$ & & & \\
\hline NCT01628380 & $\begin{array}{l}\text { Randomized, Phase III; } \\
\text { A.O. Ospedale Papa } \\
\text { Giovanni XXIII, Italy }\end{array}$ & Advanced ovarian cancer & $\begin{array}{l}\text { Cisplatin } 100 \mathrm{mg} / \mathrm{m}^{2}+ \\
\text { paclitaxel } 175 \mathrm{mg} / \mathrm{m}^{2}\end{array}$ & $\mathrm{CRS}+\mathrm{SC}$ & $\mathrm{CRS}+\mathrm{HIPEC}+\mathrm{SC}$ & \\
\hline NCT02681432 & $\begin{array}{l}\text { Randomized, Phase III; } \\
\text { Hospital General de la } \\
\text { Ciudad Real, Spain }\end{array}$ & Advanced ovarian cancer & $\begin{array}{l}\text { Paclitaxel } 175 \mathrm{mg} / \mathrm{m}^{2} \text { for } \\
60 \mathrm{mins}\end{array}$ & $\mathrm{CRS}+\mathrm{SC}$ & $\mathrm{CRS}+\mathrm{HIPEC}+\mathrm{SC}$ & \\
\hline
\end{tabular}

Abbreviations: SC, systemic chemotherapy; CRS, cytoreductive surgery; PDS, primary debulking surgery; IDS, interval debulking surgery; PFS, progression-free survival; OS, overall survival. 
United States (NCT03772028), the CHIPPI trial in France (NCT03842982), the HIPECOC trial (NC04280185) and EHTASEOCCS trial (NCT03373058) both in China.

\subsubsection{Interval CRS/debulking}

The OVHIPEC-1 trial showed a benefit in both PFS and OS with the addition of HIPEC to interval CRS compared to interval CRS alone [5]. The use of HIPEC led to a reduction in the risk of death by $33 \%$ [HR: $0.67 ; 95 \%$ CI: $0.48-0.94 ; p$-value $=0.02$ ] [5]. Though the morbidity and mortality were similar in both arms, certain complications like infection and thromboembolism and the rate of stoma formation were more in the HIPEC arm. There were many criticisms of this trial [90,91]. The survival rates (PFS-10 m and OS-41 m) were similar to studies in which no HIPEC was used. This trial had a very stringent follow-up protocol and strict criteria for diagnosis of recurrence due to which the recurrences may have been reported earlier than usual. Second, since randomization was performed intraoperatively, survival was calculated from the date of surgery and not the time of starting NACT (approximately reduction of $3 \mathrm{~m}$ in PFS and OS). The intraoperative randomization was considered improper and fraught with bias. However, HIPEC is performed only in patients with residual disease measuring less than $2.5 \mathrm{~mm}$ and only those patients in whom a complete CRS is feasible or has already been achieved can be randomized to evaluate the benefit of HIPEC over CRS alone. The sample size was considered small and the primary end-point that is PFS was not met with. The long recruitment period of 9 years and reduced benefit in patients recruited at the most experienced centers were other criticisms. Despite these limitations, an OS benefit of $12 \mathrm{~m}$ cannot be ignored and HIPEC has now been included in many national and international guidelines including the NCCN guidelines as a treatment option for patients undergoing interval CRS.

In the trial from Korea discussed in the previous section, there was a trend towards a longer PFS and OS with HIPEC in patients who had a follow up of more than two years [90]. The trial has been completed but the final results have not been disclosed or published. Ongoing clinical trial on HIPEC in addition to interval CRS are listed in Table 5.

\subsection{Morbidity of HIPEC}

One of the main criticisms of HIPEC has been the morbidity and the subsequent impact on starting adjuvant therapy. Published randomized trials on HIPEC and large cohort studies have shown that the morbidity of HIPEC is acceptable (Table 6, Ref. [4,63,88,92,93]. In the OVIHIPEC1 , the rate of stoma formation was more in the HIPEC arm but this can be avoided by placing an additional layer of interrupted sutures around the rectal anastomosis as described by Sugarbaker [4,94]. Most of the times, the mid-rectum is preserved and this additional layer of sutures can be easily placed. The other specific toxicity is nephrotoxicity (with the use of Cisplatin HIPEC) that can be prevented by using the appropriate dose of Cisplatin and nephroprotective drugs like sodium thiosulfate in the perioperative period [95].

In our retrospective study described previously in this manuscript, the combination of TPP and HIPEC had an acceptable morbidity at different time-points. In both the univariate and multivariate analysis, HIPEC did not have an impact on the morbidity.

\section{Maintenance therapy after completion of first-line therapy}

Given the high incidence of occult disease and peritoneal recurrence the benefit of maintenance cytotoxic chemotherapy has been investigated in several studies. There was no benefit in OS in any of these studies (GOG178, AGO-GINECO, MITO-1 and After-6) [91,9698]. Contrary to this, some of the trials evaluating the role of targeted therapies have shown a clinical benefit and some of these drugs are recommended as maintenance therapy for advanced EOC [99].

\section{PARP inhibitors}

Poly (ADP-ribose) polymerase 1 (PARP1) is an important protein in the base excision repair (BER) pathway for DNA single strand breaks (SSBs) and double strand breaks (DSBs) as well [100]. These breaks are repaired by the homologous recombination repair (HRR) pathway in which the PARP enzymes play an important role [101]. In patients with impaired or deficient HRR like those with BRCA mutations, inhibition of PARP enzymes by PARP inhibitors (PARPi) leads to repair by non-homologous end joining (NHEJ) which leads to genomic instability and cell death. This mechanism of action of PARPi in known as synthetic lethality [102]. Homologous recombination repair deficiency (HRD) is seen in $50 \%$ of the high grade serous ovarian cancers of which about $20 \%$ are related to germline and somatic BRCA mutations and the rest to mutations in the non-BRCA HRR genes ATM, ATR, RAD 51, PALB2 [103,104].

The SOLO1, a randomized, double-blind, phase III trial randomized 391 patients with stages IIIC-IV high grade serous or endometrioid ovarian cancers to either a placebo or to olaparib (300 $\mathrm{mg}$ twice a day) for two years or till disease progression after completion of first line chemotherapy [105]. All patients had BRCA 1 or 2 germline or somatic mutations. Median PFS from randomization, was 13.8 months in the placebo arm and was not reached in the olaparib arm (HR 0.30; 95\% CI: 0.23 to 0.41 , $p<0.01)$. The PFS rate at 3 years was $60 \%$ in the olaparib arm versus $27 \%$ in the placebo arm. The median PFS to the first subsequent therapy were 51.8 months in the olaparib arm and 15.1 months in the placebo arm (HR 0.30; 95\% CI: 0.22 to 0.40 ). At the time of PFS analysis, the interim OS data were immature. Serious adverse effects were seen 
Table 6. Comparison of major morbidity and mortality following CRS and HIPEC and TPP and HIPEC for EOC.

\begin{tabular}{|c|c|c|c|c|c|c|}
\hline Year [ref.] & No of patients & $\begin{array}{l}\text { Overall grade } \\
3-4 \text { morbidity }\end{array}$ & $\begin{array}{l}\text { Post-operative } \\
\text { mortality }\end{array}$ & HIPEC arm & CRS alone arm & Most common complications \\
\hline 2018 [4] & 245 & $25.3 \%$ & $0.4 \%$ & $27 \%$ & $25 \%$ & Abdominal pain, infection, ileus \\
\hline $2021[88]$ & 584 & $23.2 \%$ & $0 \%$ & $28.1 \%$ & $11.5 \%$ & $\begin{array}{l}\text { Electrolyte imbalance, anemia, } \\
\text { leukopenia, neutropenia }\end{array}$ \\
\hline $2012[92]$ & $\begin{array}{l}566 \text { (advanced and } \\
\text { recurrent both) }\end{array}$ & $31.3 \%$ & $0.8 \%$ & - & - & $\begin{array}{l}\text { Leukopenia, haemorrhage, } \\
\text { digestive fistula }\end{array}$ \\
\hline 2016 [93] & 226 & $14.1 \%$ & $\begin{array}{l}2.5 \% \text { (for the } \\
\text { whole cohort of } \\
511 \text { patients) }\end{array}$ & - & - & - \\
\hline $2021[63]$ & 90 & $33.3 \%$ & $4.4 \%$ & $35.0 \%$ & $29.8 \%$ & $\begin{array}{c}\text { Respiratory complications, } \\
\text { intraabdominal fluid collections, } \\
\text { wound dehiscence; intraabdominal } \\
\text { abscess }\end{array}$ \\
\hline
\end{tabular}

in $21 \%$ in the experimental arm and in $12 \%$ in the control arm. There were no treatment related deaths in either arm. In a subsequent subgroup analysis of the trial, a reduced risk of recurrence with olaparib was seen in patients undergoing primary or interval cytoreductive surgery, those with a $\mathrm{CC}-0$ resection as well as those with residual disease, in patients with a complete or partial response to first line therapy at baseline and in patients with BRCA1 and BRCA 2 mutations both [106].

PRIMA/ENGOT-OV26/GOG-3012 randomized 733 women with stages I-IV ovarian cancer to the PARPi Niraparib or placebo after completion of first line chemotherapy [107]. 373 patients $(50.9 \%)$ were HRD positive, including 223 BRCA mutated patients. The PFS was statistically longer in the HRD population (median PFS of 21.9 months versus 10.4 months) and in the overall population (median PFS of 13.8 months vs. 8.2 months) with an HR of respectively $0.43(95 \% \mathrm{CI}, 0.31$ to $0.59, p<0.001)$ and $0.62(95 \%$ CI, 0.50 to $0.76, p<0.001)$. OS data are not yet mature. In the unplanned analysis of the HRP group, there was a modest benefit of Niriparib over a placebo (median PFS of 8.1 months vs. 5.4 months; HR of 0.68 (95\% CI, 0.49 to 0.94 ).

VELIA/GOG-3005 is a prospective randomized phase III trial that randomized 1140 patients with stages III-IV of EOC to 3 arms: Arm A-Patients received low-dose veliparib (150 mg twice daily) throughout chemotherapy followed by full dose (300 $\mathrm{mg}$ twice daily) in maintenance; Arm B-veliparib only in combination with chemotherapy followed by placebo maintenance; Arm C- placebo in combination with chemotherapy and during maintenance in the arm C. 298 (26\%) had BRCA mutations; 329 (29\%) were HRD without BRCA mutations; and 33\% were HRP [108]. Veliparib in arm A was associated with an improved PFS over chemotherapy alone ( $\operatorname{arm} \mathrm{C}$ ) but not in the concomitant veliparib arm B. The median PFS in the BRCA mutated cohort was 34.7 vs. 22 months with an HR of 0.44 (95\% CI, 0.28 to $0.68, p<0.001$ ) with and without veliparib respectively, in the HRD cohort it was 31.9 vs. 20.5 months corresponding to an HR of 0.57 (95\% CI, 0.43 to $0.76, p<0.001)$ and 23.5 vs. 17.3 months in the intention to treat (ITT) cohort corresponding to an HR of 0.68 (95\% CI, 0.56 to $0.83, p<0.001)$. They were no clinically significant difference between the two arms in quality-of-life parameters.

The PAOLA-1/ENGOT-ov25 trial randomized 806 patients with stages III-IV of high grade serous and endometrioid EOC to bevacizumab and olaparib or bevacizumab and placebo after completion of first line chemotherapy [109]. Olaparib or placebo was continued for 24 months and bevacizumab for 15 months. $30 \%$ had stage IV high grade serous EOC, $60 \%$ underwent complete cytoreduction, $70 \%$ had no evidence of disease or complete response to chemotherapy and $30 \%$ had a deleterious, germline or somatic BRCA mutation. The median PFS was statistically longer in the olaparib arm compared to the placebo arm [22.1 months versus 16.6 months; HR of 0.59 (95\% CI, 0.49 to $0.72, p<0.001)$ ]. In the BRCA mutated population, the median PFS was 37.2 vs. 21.7 months in favor of the combination [HR of 0.31 (95\% CI, 0.20 to 0.47$)$ ] and in HRD population (including BRCA mutated patients) the median PFS was 37.2 vs. 17.7 months [HR of $0.33(95 \%$ CI, 0.25 to 0.45$)$ ] also favoring the olaparib arm. No benefit of olaparib was seen in the HRP population. The incidence of cardio-vascular or nephrotoxic adverse events frequently observed with bevacizumab was not higher in the combination arm. No differences in health-related quality of life were observed in the 2 arms.

\section{Bevacizumab}

The vascular endothelial growth factor (VEGF) that promotes angiogenesis, has been linked to hematogeneous spread and formation of ascites in ovarian cancer [110]. The benefit of using bevacizumab as concomitant adjuvant and maintenance therapy has been evaluated in two randomized trials. The GOG 218 trial randomized 1873 patients 
with incompletely resected stage III and IV disease to the anti-VEGF agent bevacizumab administered during adjuvant chemotherapy and as maintenance therapy thereafter for 12-15 months or adjuvant chemotherapy alone [111]. The primary end-point was PFS. The median PFS was 14.1 months in bevacizumab-arm versus 10.3 months in the control arm [hazard ratio (HR) of 0.72 (95\% confidence interval (CI) 0.63 to $0.82, p<0.001)$ ]. There was no benefit in OS in the ITT population. A post-hoc analysis showed a benefit in OS in patients with stage III disease and suboptimal debulking and stage IV disease [112]. The ICON 7 trial randomized 1528 patients with stage I-IV to adjuvant chemotherapy with bevacizumab followed by maintenance therapy or to adjuvant chemotherapy alone [113]. The median PFS was 19.8 months in the experimental arm versus 17.4 months in the control arm, [HR of 0.87 (95\% CI 0.77 to $0.99, p=0.04)$ ]. However, OS was not significantly increased in the ITT analyses. Adverse events related to bevacizumab included hypertension, hemorrhage, thromboembolic events and gastrointestinal perforations. In both trials, the benefit in PFS benefit associated with bevacizumab was seen largely in women with sub-optimal debulking or those with stage IV disease. Patients with a CC-0 resection were not included in the GOG-218 trial and represented a minority of the population of the ICON-7 trial. Both trials only included patients undergoing primary CRS/debulking.

It was observed that the survival curves in both the bevacizumab and non-bevacizumab arms merged rapidly after the discontinuation of bevacizumab which implies that the PFS benefit was observed only during bevacizumab maintenance treatment [114]. The BOOST trial (ClinicalTrials.gov Identifier: NCT01462890) will determine if a prolonged administration of bevacizumab up to 30 months could further improve PFS.

\section{Current recommendations for maintenance therapy}

Currently, the overall survival data are not mature for any of the trials on PARP inhibitors. An update on the SOLO-1 trial showed a median PFS of $51 \mathrm{~m}$ in the olaparib arm (unpublished results). Given the marked benefit in the PFS and possibility of a reduction in PRR and ER, olaparib is recommended for maintenance therapy following completion of first-line chemotherapy for patients with BRCA mutated tumors (Table 7, Ref. [5,24-26,66,105,107,109, 111,112]) [115]. There is however, no formal analysis of either of these end-points and the trials were not designed to address these questions. The role in HRD population with no BRCA mutations is less clear and it is not recommended for patients with HRP tumors. Niriparib could be used for patients irrespective of BRCA mutation status though the evidence is less robust especially for patients having a CC0 resection [114].

Bevacizumab could be used for both HRD and HRP tumors but the evidence once again is less convincing es- pecially for patients with a $\mathrm{CC}-0$ resection. Moreover, two trials failed to show a benefit in OS except in patients with suboptimal debulking and stage IV disease and the results of the third trial are awaited. The benefit in patients with suboptimal debulking and stage IV disease is more pronounced and it may be used for these patients. The optimal duration of therapy is still under investigation [114].

The recommendation of various experts is that the use of PARP inhibitors should be guided by molecular tests for HRD and not traditional clinical factors [115].

A study on the cost effectiveness of maintenance therapies showed that none of the maintenance therapies was cost-effective when the patients had to pay for the therapy [116].

\section{Combination of TPP with other locoregional and systemic therapies}

The main cause of recurrence in ovarian cancer is the high burden of occult disease that is not eradicated effectively with systemic chemotherapy alone. In patients who have incomplete or suboptimal surgery, therapies other than $\mathrm{SC}$ are needed to eradicate this disease more effectively. TPP is a sure-shot way of addressing occult disease in the peritoneal regions that are resected. Through it, a large proportion of the occult disease is removed. However, it is likely that there is disease at some sites that is not addressed. Given the lack of evidence, it may be considered an experimental approach. HIPEC can eradicate microscopic disease but this effect is dependent at least in part on the chemosensitivity of the tumour cells and there is no objective method of assessing it. It also acts on free intraperitoneal cancer cells shed during CRS and prevents their implantation at the surgical sites. With a TPP, the residual disease in the parietal and visceral areas resected is completely removed and this represents over $80 \%$ of the areas harbouring disease in EOC. HIPEC can still eradicate disease from the peritoneum that has not been resected - the visceral peritoneum. It may thus, be assumed that the benefit of these two strategies should be additive. We performed TPP and HIPEC in combination for advanced and recurrent EOC and found the morbidity to be acceptable [63].

Similarly, PARPi and bevacizumab act on microscopic disease and systemic disease as well. PARPi have the added benefit of producing shrinkage of gross residual disease resulting in a CR. The response to PARPi is sustained compared to that obtained with bevacizumab that wears away when the drug is discontinued. EOC is a heterogeneous disease with a number of clinicopathological and molecular factors influencing the prognosis.

Thus, it is plausible that there are different subgroups of patients that benefit from each of these 4 treatment strategies or a combination of these. For example, patients who are HRP and have a poor response to SC could be the ones that benefit most from a combination of TPP and HIPEC. Clinicians often question the role of locoregional therapies 
Table 7. Platinum resistant recurrence and early recurrence reported in studies and clinical trials on TPP, HIPEC, PARPi and bevacizumab maintenance therapy.

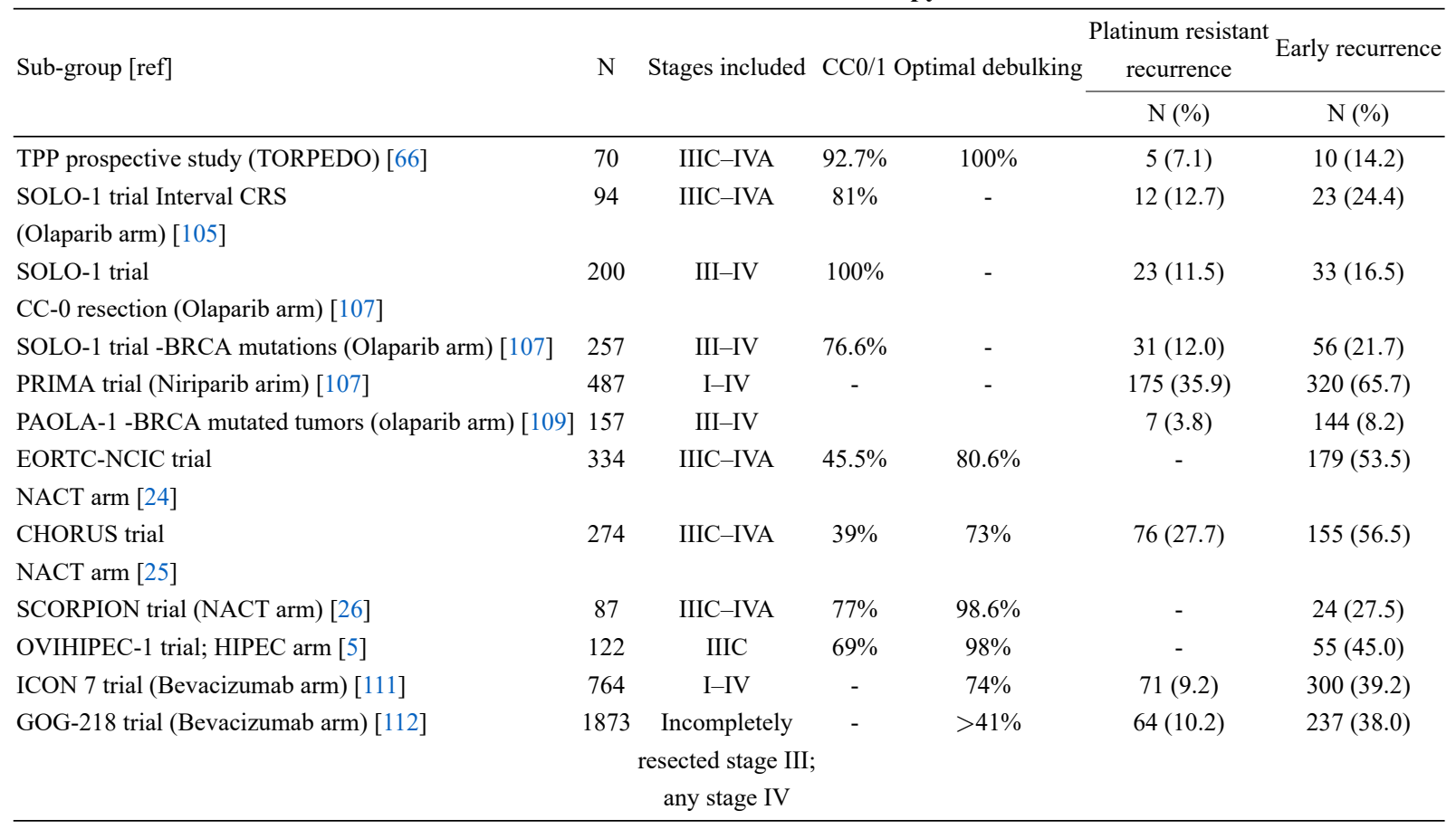

Abbreviations: TPP, total parietal peritonectomy; HIPEC, hyperthermic interaperitoneal chemotherapy; PARPi, PARP inhibitors; NACT, neoadjuvant chemotherapy.

in patients who are BRCA mutated and receiving olaparib maintenance therapy. Resistance to PARPi is a clinical problem that is a focus of current research [117]. Locoregional therapies like TPP and HIPEC could eradicate the occult disease more effectively and reduce the incidence of resistance to PARPi [117]. Most patients treated with TPP with or without HIPEC irrespective of the molecular profile may not derive much benefit from the addition of bevacizumab especially if they also have a complete morphological and biochemical response. Similarly, HIPEC may have a limited benefit in patients who have a very good response to systemic chemotherapy.

Future research should explore the role of each of these therapies in different prognostic subgroups to identify the treatments that confer the maximum benefit.

Apart from the clinic-pathological and molecular factors, other factors like the availability of surgical expertise, technology and equipment and the morbidity/toxicity and cost of each therapy have an impact of the treatment that is offered.

\section{Conclusions}

Studies on peritoneal spread and response to systemic chemotherapy EOC show that the incidence of occult disease is high in the peritoneum that appears 'normal' during surgery and is likely to be the source of recurrent disease. TPP performed along with wide resection of the visceral peritoneum could be a more effective strategy for addressing this occult disease compared to other locoregional therapies like HIPEC and systemic therapies. However, the other therapies have the benefit of addressing the areas that are not addressed by TPP. The morbidity of TPP as part of first-line therapy for EOC is acceptable. Further research is needed to demonstrate the impact of TPP on survival and both PFS and OS should be the end-points of studies evaluating its role. The evidence for the use of HIPEC, PARPi and bevacizumab is evolving.

Clinicopathological and molecular factors have identified different prognostic subgroups of ovarian cancer. Future research should aim to identify which therapies are most beneficial for each sub-group. Not just the PFS and OS but the morbidity/toxicity and cost-effectiveness of each treatment should be considered. The patterns of peritoneal spread and recurrence need further study as well.

\section{Author contributions}

$\mathrm{AB}$ - conceptualization, literature search, data collection and interpretation, analysis of data, supervision, manuscript preparation, manuscript editing, approval of the final draft. SS - conceptualization, literature search, data collection and interpretation, analysis of data, manuscript editing, approval of the final draft. PK - conceptualization, literature search, data collection and interpretation, analysis of data, manuscript preparation, manuscript editing, approval of the final draft. SM-conceptualization, literature search, data collection and interpretation, analysis of data, manuscript editing, approval of the final draft. 


\section{Ethics approval and consent to participate}

Not applicable.

\section{Acknowledgment}

The authors thank the reviewers for their very valuable comments and suggestions on this manuscript.

\section{Funding}

This research received no external funding.

\section{Conflict of interest}

The authors declare no conflict of interest.

\section{References}

[1] Lee JY, Kim S, Kim YT, Lim MC, Lee B, Jung KW, et al. Changes in ovarian cancer survival during the 20 years before the era of targeted therapy. BMC Cancer. 2018; 18: 601.

[2] Bhatt A, Glehen O. The role of Cytoreductive Surgery and Hyperthermic Intraperitoneal Chemotherapy (HIPEC) in Ovarian Cancer: A Review. Indian Journal of Surgical Oncology. 2016; 7: 188-197.

[3] Shoji T, Sato C, Tomabechi H, Takatori E, Kaido Y, Nagasawa $\mathrm{T}$, et al. Expectations and Challenges of First-Line Maintenance Therapy for Advanced Ovarian Cancer. Medicina. 2021; 57: 501 .

[4] González-Moreno S, González-Bayón LA, Ortega-Pérez G. Hyperthermic intraperitoneal chemotherapy: Rationale and technique. World Journal of Gastrointestinal Oncology. 2010; 2: 6875.

[5] van Driel WJ, Koole SN, Sikorska K, Schagen van Leeuwen $\mathrm{JH}$, Schreuder HWR, Hermans RHM, et al. Hyperthermic Intraperitoneal Chemotherapy in Ovarian Cancer. The New England Journal of Medicine. 2018; 378: 230-240.

[6] Walsh CS. Latest clinical evidence of maintenance therapy in ovarian cancer. Current Opinion in Obstetrics and Gynecology. 2020; 32: 15-21

[7] Bhatt A, Kammar P, Mehta S, Sinukumar S. ASO Author Reflections: Total Parietal Peritonectomy during Interval Cytoreductive Surgery for Advanced Ovarian Cancer-Proof-ofPrinciple and Analysis of Morbidity. Annals of Surgical Oncology. 2020; 27: 861-862.

[8] Murphy EM, Sexton R, Moran BJ. Early results of surgery in 123 patients with pseudomyxoma peritonei from a perforated appendiceal neoplasm. Diseases of the Colon and Rectum. 2007; 50: $37-42$.

[9] Kostić Z, Cuk V, Bokun R, Ignjatović D, Usaj-Knezević S, Ignjatović M. Detection of free cancer cells in peritoneal cavity in patients surgically treated for gastric adenocarcinoma. Vojnosanitetski Pregled. 2006; 63: 349-356. (In Serbian)

[10] Lemoine L, Sugarbaker P, Van der Speeten K. Pathophysiology of colorectal peritoneal carcinomatosis: Role of the peritoneum. World Journal of Gastroenterology. 2016; 22: 7692-7707.

[11] Shimotsuma M, Shields JW, Simpson-Morgan MW, Sakuyama A, Shirasu M, Hagiwara A, et al. Morpho-physiological function and role of omental milky spots as omentum-associated lymphoid tissue (OALT) in the peritoneal cavity. Lymphology. 1993; 26: 90-101.

[12] Yonemura Y, Kawamura T, Bandou E, Tsukiyama G, Endou Y, Miura M. The Natural History of Free Cancer Cells in the Peritoneal Cavity. In Gonzalez-Moreno S (ed.) Advances in peritoneal surface oncology (pp. 11-23). Springer: Berlin. 2007.

[13] Kusamura S, Baratti D, Zaffaroni N, Villa R, Laterza B, Balestra
MR, et al. Pathophysiology and biology of peritoneal carcinomatosis. World Journal of Gastrointestinal Oncology. 2010; 2: $12-18$.

[14] Bhatt A, Yonemura Y, Benzerdjeb N, Mehta S, Mishra S, Parikh $\mathrm{L}$, et al. Pathological assessment of cytoreductive surgery specimens and its unexplored prognostic potential-a prospective multi-centric study. European Journal of Surgical Oncology. 2019; 45: 2398-2404.

[15] Tan DS, Agarwal R, Kaye SB. Mechanisms of transcoelomic metastasis in ovarian cancer. The Lancet Oncology. 2006; 7: 925-934.

[16] Sehouli J, Senyuva F, Fotopoulou C, Neumann U, Denkert C, Werner L, et al. Intra-abdominal tumor dissemination pattern and surgical outcome in 214 patients with primary ovarian cancer. Journal of Surgical Oncology. 2009; 99: 424-427.

[17] Minig L, Patrono MG, Gallego RA, de Bernabé JV, Diaz-Padilla I. Ovarian Cancer: A Clinical and Translational Update. In Ivan Díaz-Padilla (ed.) Surgical treatment of ovarian cancer (pp. 161). InTech: Croatia. 2013.

[18] Azaïs H, Vignion-Dewalle AS, Carrier M, Augustin J, Da Maïa E, Penel A, et al. Microscopic Peritoneal Residual Disease after Complete Macroscopic Cytoreductive Surgery for Advanced High Grade Serous Ovarian Cancer. Journal of Clinical Medicine. 2020; 10: 41.

[19] Hynninen J, Lavonius M, Oksa S, Grénman S, Carpén O, Auranen A. Is perioperative visual estimation of intra-abdominal tumor spread reliable in ovarian cancer surgery after neoadjuvant chemotherapy? Gynecologic Oncology. 2013; 128: 229-232.

[20] Bhatt A, Kammar P, Sinukumar S, Parikh L, Jumale N, Shaikh $\mathrm{S}$, et al. Total parietal peritonectomy can be performed with acceptable morbidity in patients with advanced ovarian cancer following neoadjuvant chemotherapy: results from a prospective multi-centric study. Annals of Surgical Oncology. 2021; 28 : $1118-1129$

[21] Lim MC, Song YJ, Seo SS, Yoo CW, Kang S, Park SY. Residual cancer stem cells after interval cytoreductive surgery following neoadjuvant chemotherapy could result in poor treatment outcomes for ovarian cancer. Onkologie. 2010; 33: 324-330.

[22] Luo Y, Lee M, Kim HS, Chung HH, Song YS. Effect of neoadjuvant chemotherapy on platinum resistance in stage IIIC and IV epithelial ovarian cancer. Medicine. 2016; 95: e4797.

[23] Bhatt A, Yonemura Y, Mehta S, Benzerdjeb N, Kammar P, Parikh L, et al. Target region resection in patients undergoing cytoreductive surgery for peritoneal metastases-is it necessary in absence of visible disease? European Journal of Surgical Oncology. 2020; 46: 582-589.

[24] Vergote I, Trope CG, Amant F, Kristensen GB, Ehlen T, Johnson $\mathrm{N}$, et al. Neoadjuvant Chemotherapy or Primary Surgery in Stage IIIC or IV Ovarian Cancer. New England Journal of Medicine. 2010; 363: 943-953.

[25] Kehoe S, Hook J, Nankivell M, Jayson GC, Kitchener H, Lopes $\mathrm{T}$, et al. Primary chemotherapy versus primary surgery for newly diagnosed advanced ovarian cancer (CHORUS): an open-label, randomised, controlled, non-inferiority trial. The Lancet. 2015; 386: 249-257.

[26] Fagotti A, Ferrandina MG, Vizzielli G, Pasciuto T, Fanfani F, Gallotta $\mathrm{V}$, et al. Randomized trial of primary debulking surgery versus neoadjuvant chemotherapy for advanced epithelial ovarian cancer (SCORPION-NCT01461850). International Journal of Gynecologic Cancer. 2020; 30: 1657-1664.

[27] Chi DS, Musa F, Dao F, Zivanovic O, Sonoda Y, Leitao MM et al. An analysis of patients with bulky advanced stage ovarian, tubal, and peritoneal carcinoma treated with primary debulking surgery (PDS) during an identical time period as the randomized EORTC-NCIC trial of PDS vs neoadjuvant chemotherapy (NACT). Gynecologic Oncology. 2012; 124: 10-14. 
[28] Rauh-Hain JA, Rodriguez N, Growdon WB, Goodman AK, Boruta DM 2nd, Horowitz NS, et al. Primary debulking surgery versus neoadjuvant chemotherapy in stage IV ovarian cancer. Annals of Surgical Oncology. 2012; 19: 959-965.

[29] Bhatt A, Sinukumar S, Mehta S, Damodaran D, Zaveri S, Kammar $\mathrm{P}$, et al. Patterns of pathological response to neoadjuvant chemotherapy and its clinical implications in patients undergoing interval cytoreductive surgery for advanced serous epithelial ovarian cancer- a study by the Indian Network for Development of Peritoneal Surface Oncology (INDEPSO). European Journal of Surgical Oncology. 2019; 45: 666-671.

[30] Bhatt A, Bakrin N, Kammar P, Mehta S, Sinukumar S, Parikh $\mathrm{L}$, et al. Distribution of residual disease in the peritoneum following neoadjuvant chemotherapy in advanced epithelial ovarian cancer and its potential therapeutic implications. European Journal of Surgical Oncology. 2021; 47: 181-187.

[31] Amate P, Huchon C, Dessapt AL, Bensaid C, Medioni J, Le Frère Belda MA, et al. Ovarian cancer: sites of recurrence. International Journal of Gynecological Cancer. 2013; 23: 1590 1596.

[32] Tanner EJ, Black DR, Zivanovic O, Kehoe SM, Dao F, Konner JA, et al. Patterns of first recurrence following adjuvant intraperitoneal chemotherapy for stage IIIC ovarian cancer. Gynecologic Oncology. 2012; 124: 59-62.

[33] Ceresoli M, Verrengia A, Montori G, Busci L, Coccolini F, Ansaloni L, et al. Effect of cytoreductive surgery and hyperthermic intraperitoneal chemotherapy on relapse pattern in primary epithelial ovarian cancer: a propensity score based case-control study. Journal of Gynecologic Oncology. 2018; 29: e53.

[34] Sinukumar S, Damodaran D, Ray M, Mehta S, Paul L, Bhatt A. Pattern of recurrence after interval cytoreductive surgery and HIPEC following neoadjuvant chemotherapy in primary advanced stage IIIC/IVA epithelial ovarian cancer. European Journal of Surgical Oncology. 2021; 47: 1427-1433.

[35] Gadducci A, Cosio S. Surveillance of patients after initial treatment of ovarian cancer. Critical Reviews in Oncology/Hematology. 2009; 71: 43-52.

[36] Vaidya AP, Curtin JP. The follow-up of ovarian cancer. Seminars in Oncology. 2003; 30: 401-412.

[37] Bhatt A, Bakrin N, Gertych W, Kammar P, Parikh L, Sheth S, et $a l$. Extent and distribution of peritoneal disease in patients undergoing cytoreductive surgery for first platinum sensitive recurrence in ovarian cancer and its potential therapeutic implications. European Journal of Surgical Oncology. 2020; 46: 2276-2282.

[38] Chi DS, McCaughty K, Diaz JP, Huh J, Schwabenbauer S, Hummer AJ, et al. Guidelines and selection criteria for secondary cytoreductive surgery in patients with recurrent, platinumsensitive epithelial ovarian carcinoma. Cancer. 2006; 106: 1933-1939.

[39] Ferrandina G, Legge F, Salutari V, Paglia A, Testa A, Scambia G. Impact of pattern of recurrence on clinical outcome of ovarian cancer patients: clinical considerations. European Journal of Cancer. 2006; 42: 2296-2302.

[40] Meigs JV. Tumors of the female pelvic organs. MacMillan: London. 1934.

[41] Hoskins WJ, Bundy BN, Thigpen JT, Omura GA. The influence of cytoreductive surgery on recurrence-free interval and survival in small-volume stage III epithelial ovarian cancer: A Gynecologic Oncology Group study. Gynecologic Oncology. 1992; 47 : 159-166.

[42] Bristow RE, Tomacruz RS, Armstrong DK, Trimble EL, Montz FJ. Survival Effect of Maximal Cytoreductive Surgery for Advanced Ovarian Carcinoma during the Platinum Era: A MetaAnalysis. Journal of Clinical Oncology. 2002; 20: 1248-1259.

[43] Chi DS, Eisenhauer EL, Zivanovic O, Sonoda Y, Abu-Rustum $\mathrm{NR}$, Levine DA, et al. Improved progression-free and overall survival in advanced ovarian cancer as a result of a change in surgical paradigm. Gynecologic Oncology. 2009; 114: 26-31.

[44] Aletti GD, Dowdy SC, Podratz KC, Cliby WA. Surgical treatment of diaphragm disease correlates with improved survival in optimally debulked advanced stage ovarian cancer. Gynecologic Oncology. 2006; 100: 283-287.

[45] Eisenhauer EL, Abu-Rustum NR, Sonoda Y, Levine DA, Poynor EA, Aghajanian C, et al. The addition of extensive upper abdominal surgery to achieve optimal cytoreduction improves survival in patients with stages IIIC-IV epithelial ovarian cancer. Gynecologic Oncology. 2006; 103: 1083-1090.

[46] Colombo PE, Mourregot A, Fabbro M, Gutowski M, SaintAubert B, Quenet F, et al. Aggressive surgical strategies in advanced ovarian cancer: a monocentric study of 203 stage IIIC and IV patients. European Journal of Surgical Oncology. 2009; 35: 135-143.

[47] Wallace S, Kumar A, Mc Gree M, Weaver A, Mariani A, Langstraat $\mathrm{C}$, et al. Efforts at maximal cytoreduction improve survival in ovarian cancer patients, even when complete gross resection is not feasible. Gynecologic Oncology. 2017; 145: 2126.

[48] Chang SJ, Bristow RE. Evolution of surgical treatment paradigms for advanced-stage ovarian cancer: redefining 'optimal' residual disease. Gynecologic Oncology. 2012; 125: 483492.

[49] Lee JY, Kim S, Kim YT, Lim MC, Lee B, Jung K, et al. Changes in ovarian cancer survival during the 20 years before the era of targeted therapy. BMC Cancer. 2018; 18: 601.

[50] Pentheroudakis G, Pavlidis N. Serous papillary peritoneal carcinoma: Unknown primary tumour, ovarian cancer counterpart or a distinct entity? a systematic review. Critical Reviews in Oncology/Hematology. 2010; 75: 27-42.

[51] NCCN guidelines. 2021. Available at: https://www.ncen.org/p rofessionals/physician\gls/pdf/ovarian.pdf (Accessed: 12 January 2021).

[52] Bakrin N, Gladieff L. Malignant epithelial ovarian cancer: Role of intra-peritoneal chemotherapy and hyperthermic intra peritoneal chemotherapy(HIPEC): Article drafted from the French Guidelines in oncology entitled "Initial management of patients with epithelial ovarian cancer" developed by FRANCOGYN, CNGOF, SFOG, GINECO-ARCAGY under the aegis of CNGOF and endorsed by INCa. Gynecologie Obstetrique Fertilite et Senologie. 2019; 47: 214-221. (In French)

[53] Colombo N, Sessa C, du Bois A, Ledermann J, McCluggage WG, McNeish I, et al. ESMO-ESGO consensus conference recommendations on ovarian cancer: pathology and molecular biology, early and advanced stages, borderline tumours and recurrent disease. Annals of Oncology. 2019; 30: 672-705.

[54] Sugarbaker PH. Peritonectomy procedures. Annals of Surgery. 1995; 221: 29-42.

[55] Sabel MS, Diehl KM, Chang AE. Principles of Surgical Therapy in Oncology. In Chang AE, et al. (eds.) Oncology. Springer: New York. 2006

[56] van 't Sant I, Engbersen MP, Bhairosing PA, Lambregts DMJ, Beets-Tan RGH, van Driel WJ, et al. Diagnostic performance of imaging for the detection of peritoneal metastases: a metaanalysis. European Radiology. 2020; 30: 3101-3112.

[57] Goswami G, Kammar P, Mangal R, Shaikh S, Patel MD, Bhatt A. Accuracy of CT Scan in Predicting the Surgical $\mathrm{PCI}$ in Patients Undergoing Cytoreductive Surgery with/without HIPEC - a Prospective Single Institution Study. Indian Journal of Surgical Oncology. 2019; 10: 296-302.

[58] Baratti D, Kusamura S, Cabras AD, Deraco M. Cytoreductive Surgery with Selective Versus Complete Parietal Peritonectomy Followed by Hyperthermic Intraperitoneal Chemotherapy in $\mathrm{Pa}-$ tients with Diffuse Malignant Peritoneal Mesothelioma: a Con- 
trolled Study. Annals of Surgical Oncology. 2012; 19: 14161424.

[59] Deraco M, Sinukumar S, Salcedo-Hernández RA, Rajendra VJ, Baratti D, Guaglio M, et al. Clinico-pathological outcomes after total parietal peritonectomy, cytoreductive surgery and hyperthermic intraperitoneal chemotherapy in advanced serous papillary peritoneal carcinoma submitted to neoadjuvant systemic chemotherapy- largest single institute experience. European Journal of Surgical Oncology. 2019; 45: 2103-2108.

[60] Sugarbaker PH. Peritoneum as the first-line of defense in carcinomatosis. Journal of Surgical Oncology. 2007; 95: 93-96.

[61] Sinukumar S, Rajan F, Mehta S, Damodaran D, Zaveri S, Kammar $\mathrm{P}$, et al. A comparison of outcomes following total and selective peritonectomy performed at the time of interval cytoreductive surgery for advanced serous epithelial ovarian, fallopian tube and primary peritoneal cancer - a study by INDEPSO. European Journal of Surgical Oncology. 2021; 47: 75-81.

[62] Yokosu K, Tanabe H, Nomura S, Ozone H, Saito M, Takano H, et al. Total parietal peritonectomy in primary debulking surgery for advanced ovarian cancer. Gynecologic Oncology Reports. 2021; 37: 100805 .

[63] Bhatt A, Kammar P, Sinukumar S, Goswami G, Mishra B, Bhavsar M, et al. Perioperative outcomes in patients treated with total parietal peritonectomy and multi-visceral resections with or without HIPEC at different time points in the history of advanced ovarian cancer. European Journal of Gynaecological Oncology. 2021; 42: 711-720.

[64] Aletti GD, Dowdy SC, Podratz KC, Cliby WA. Relationship among surgical complexity, short-term morbidity, and overall survival in primary surgery for advanced ovarian cancer. American Journal of Obstetrics and Gynecology. 2007; 197: 676.e1676.e7.

[65] Somashekhar SP, Ashwin KR, Kumar R, Ramya Y, Zaveri SS, Rauthan A. Comparison of Outcomes Following Complete and Selective Parietal Peritonectomy during Cytoreductive Surgery and Hyperthermic Intraperitoneal Chemotherapy for Advanced Epithelial Ovarian Cancer: A Study by Indian Society of Peritoneal Surface Malignancies (ISPSM). Indian Journal of Gynecologic Oncology. 2018; 16: 71.

[66] Bhatt A, Sinukumar S, Parikh L, Mehta S, Shaikh S, Jumle N, et al. Total parietal peritonectomy performed during interval cytoreductive surgery for advanced epithelial serous ovarian cancer results in a low incidence of platinum resistant recurrenceresults of a prospective multi-centre study. European Journal of Surgical Oncology. 2021; 47: 2150-2157.

[67] Böhm S, Faruqi A, Said I, Lockley M, Brockbank E, Jeyarajah A, et al. Chemotherapy Response Score: Development and Validation of a System to Quantify Histopathologic Response to Neoadjuvant Chemotherapy in Tubo-Ovarian HighGrade Serous Carcinoma. Journal of Clinical Oncology. 2015; 33: 2457-2463.

[68] Liang WF, Li H, Wu JY, Liu CH, Wu MF, Li J. Identification of Ovarian Cancer Patients Most Likely to Achieve Chemotherapy Response Score 3 Following Neoadjuvant Chemotherapy: Development of a Predictive Nomogram. Frontiers in Oncology. 2020; 10: 560888.

[69] Fischer J, Eglinton TW, Richards SJ, Frizelle FA. Predicting pathological response to chemoradiotherapy for rectal cancer: a systematic review. Expert Review of Anticancer Therapy. 2021; 21: 489-500.

[70] Bhatt A, Benzerdjeb N, Mishra S, Glehen O. Therapeutic Rationale and Data Set for Reporting Cytoreductive Surgery Specimens. In Glehen O, Bhatt A (eds.) Pathology of Peritoneal Metastases. Springer: Singapore. 2020.

[71] Kammar P, Bhatt A, Anam J, Waghoo S, Pandey J, Mehta S. Correlation between Pelvic Peritoneal Disease and Nodal Metas- tasis in Advanced Ovarian Cancer: can Intraoperative Findings Define the need for Systematic Nodal Dissection? Indian Journal of Surgical Oncology. 2019; 10: 84-90.

[72] Harter P, Sehouli J, Lorusso D, Reuss A, Vergote I, Marth C, et al. A Randomized Trial of Lymphadenectomy in Patients with Advanced Ovarian Neoplasms. New England Journal of Medicine. 2019; 380: 822-832.

[73] Bamias A, Bamia C, Zagouri F, Kostouros E, Kakoyianni $\mathrm{K}$, Rodolakis A, et al. Improved survival trends in platinumresistant patients with advanced ovarian, fallopian or peritoneal cancer treated with first-line paclitaxel/platinum chemotherapy: the impact of novel agents. Oncology. 2013; 84: 158-165.

[74] Moran BJ, Tzivanakis A. The concept of "Obstruction-Free Survival" as an outcome measure in advanced colorectal cancer management. Pleura and Peritoneum. 2018; 3: 20180101.

[75] Paoletti X, Lewsley LA, Daniele G, Cook A, Yanaihara N, Tinker A, et al. Assessment of Progression-Free Survival as a Surrogate End Point of Overall Survival in First-Line Treatment of Ovarian Cancer. JAMA Network Open. 2020; 3: e1918939.

[76] Flessner MF. The transport barrier in intraperitoneal therapy. American Journal of Physiology - Renal Physiology. 2005; 288: F433-F442.

[77] Flessner MF. Intraperitoneal drug therapy: physical and biological principles. Cancer Treatment and Research Communications. 2007; 134: 131-152.

[78] Yonemura Y. Trans-lymphatic metastasis. In Yonemura Y (ed.) Atlas and principles of peritonectomy for peritoneal surface malignancy. Kyoto: NPO to Support Peritoneal Surface Malignancy (pp. 188-206). NPO: Kyoto, Japan. 2012.

[79] Yonemura Y, Canbay E, Endou Y, Ishibashi H, Mizumoto A Mechanisms of the formation of peritoneal surface malignancy on omental milky spots from low grade appendiceal mucinous carcinoma. Journal of Clinical Oncology. 2014; 4: 2.

[80] Solass W, Herbette A, Schwarz T, Hetzel A, Sun JS, Dutreix M, et al. Therapeutic approach of human peritoneal carcinomatosis with Dbait in combination capnoperitoneum: proof of concept. Surgical Endoscopy. 2012; 26: 847-852.

[81] Khosrawipour V, Khosrawipour T, Diaz-Carballo D, Forster E, Zieren J, Giger-Pabst U. Exploring the Spatial Drug Distribution Pattern of Pressurized Intraperitoneal Aerosol Chemotherapy (PIPAC). Annals of Surgical Oncology. 2016; 23: 1220 1224.

[82] Yonemura Y, Sako S, Wakama S, Ishibashi H, Mizumoto A, Takao N, et al. History of Peritoneal Surface Malignancy Treatment in Japan. Indian Journal of Surgery. 2019; 10: 3-11.

[83] Sticca RP, Dach BW. Rationale for hyperthermia with intraoperative intraperitoneal chemotherapy agents. Surgical Oncology Clinics of North America. 2003; 12: 689-701.

[84] Sugarbaker PH. Laboratory and clinical basis for hyperthermia as a component of intracavitary chemotherapy. International Journal of Hyperthermia. 2007; 23: 431-442.

[85] Chiva LM, Gonzalez-Martin A. A critical appraisal of hyperthermic intraperitoneal chemotherapy (HIPEC) in the treatment of advanced and recurrent ovarian cancer. Gynecologic Oncology. 2015 ; 136: 130-135.

[86] Huo YR, Richards A, Liauw W, Morris DL. Hyperthermic intraperitoneal chemotherapy (HIPEC) and cytoreductive surgery (CRS) in ovarian cancer: a systematic review and meta-analysis. European Journal of Surgical Oncology. 2015; 41: 1578-1589.

[87] Zhang G, Zhu Y, Liu C, Chao G, Cui R, Zhang Z. The prognosis impact of hyperthermic intraperitoneal chemotherapy (HIPEC) plus cytoreductive surgery (CRS) in advanced ovarian cancer: the meta-analysis. Journal of Ovarian Research. 2019; 12: 33.

[88] Lei Z, Wang Y, Wang J, Wang K, Tian J, Zhao Y, et al. Evaluation of Cytoreductive Surgery with or without Hyperthermic Intraperitoneal Chemotherapy for Stage III Epithelial Ovarian 
Cancer. JAMA Network Open. 2020; 3: e2013940.

[89] Lim MC, Chang SJ, Yoo HJ, Nam B, Bristow R, Park S. Randomized trial of hyperthermic intraperitoneal chemotherapy (HIPEC) in women with primary advanced peritoneal, ovarian, and tubal cancer. Journal of Clinical Oncology. 2017; 35: 55205520 .

[90] Spriggs DR, Zivanovic O. Ovarian Cancer Treatment - are we Getting Warmer? New England Journal of Medicine. 2018; 378 : 293-294.

[91] Vergote I, Chiva L, du Bois A. Hyperthermic Intraperitoneal Chemotherapy in Ovarian Cancer. The New England Journal of Medicine. 2018; 378: 1362-1363.

[92] Bakrin N, Bereder JM, Decullier E, Classe JM, Msika S, Lorimier G, et al. Peritoneal carcinomatosis treated with cytoreductive surgery and Hyperthermic Intraperitoneal Chemotherapy (HIPEC) for advanced ovarian carcinoma: A French multicentre retrospective cohort study of 566 patients. European Journal of Surgical Oncology. 2014; 39: 1435-1443.

[93] Di Giorgio A, De Iaco P, De Simone M, Garofalo A, Scambia $\mathrm{G}$, Pinna AD, et al. Cytoreduction (Peritonectomy Procedures) Combined with Hyperthermic Intraperitoneal Chemotherapy (HIPEC) in Advanced Ovarian Cancer: Retrospective Italian Multicenter Observational Study of 511 Cases. Annals of Surgical Oncology. 2017; 24: 914-922.

[94] Sugarbaker PH. Avoiding Diverting Ileostomy in Patients Requiring Complete Pelvic Peritonectomy. Annals of Surgical Oncology. 2016; 23: 1481-1485.

[95] Laplace N, Kepenekian V, Friggeri A, Vassal O, Ranchon F, Rioufol C, et al. Sodium thiosulfate protects from renal impairement following hyperthermic intraperitoneal chemotherapy (HIPEC) with Cisplatin. International Journal of Hyperthermia. 2020; 37: 897-902.

[96] Markman M, Liu PY, Moon J, Monk BJ, Copeland L, Wilczynski S, et al. Impact on survival of 12 versus 3 monthly cycles of paclitaxel $(175 \mathrm{mg} / \mathrm{m} 2)$ administered to patients with advanced ovarian cancer who attained a complete response to primary platinum-paclitaxel: Follow-up of a Southwest Oncology Group and Gynecologic Oncology Group phase 3 trial. Gynecologic Oncology. 2009; 114: 195-198.

[97] Pfisterer J, Weber B, Reuss A, Kimmig R, du Bois A, Wagner $\mathrm{U}$, et al. Randomized Phase III Trial of Topotecan Following Carboplatin and Paclitaxel in first-line Treatment of Advanced Ovarian Cancer: a Gynecologic Cancer Intergroup Trial of the AGO-OVAR and GINECO. Journal of the National Cancer Institute. 2006; 98: 1036-1045.

[98] De Placido S, Scambia G, Di Vagno G, Naglieri E, Lombardi $\mathrm{AV}$, Biamonte R, et al. Topotecan Compared with no Therapy after Response to Surgery and Carboplatin/Paclitaxel in Patients with Ovarian Cancer: Multicenter Italian Trials in Ovarian Cancer (MITO-1) Randomized Study. Journal of Clinical Oncology. 2004; 22: 2635-2642.

[99] Pecorelli S, Favalli G, Gadducci A, Katsaros D, Panici PB, Carpi A, et al. Phase III Trial of Observation Versus Six Courses of Paclitaxel in Patients with Advanced Epithelial Ovarian Cancer in Complete Response after Six Courses of Paclitaxel/PlatinumBased Chemotherapy: Final Results of the after-6 Protocol 1. Journal of Clinical Oncology. 2009; 27: 4642-4648.

[100] Hoeijmakers JH. Genome maintenance mechanisms for preventing cancer. Nature. 2001; 411: 366-374.

[101] Farmer H, McCabe N, Lord CJ, Tutt ANJ, Johnson DA, Richardson TB, et al. Targeting the DNA repair defect in BRCA mutant cells as a therapeutic strategy. Nature. 2005; 434: $917-$ 921.
[102] McLornan DP, List A, Mufti GJ. Applying synthetic lethality for the selective targeting of cancer. The New England Journal of Medicine. 2014; 371: 1725-1735.

[103] Mirza MR, Pignata S, Ledermann JA. Latest clinical evidence and further development of PARP inhibitors in ovarian cancer. Annals of Oncology. 2018; 29: 1366-1376.

[104] Walsh T, Casadei S, Lee MK, Pennil CC, Nord AS, Thornton $\mathrm{AM}$, et al. Mutations in 12 genes for inherited ovarian, fallopian tube, and peritoneal carcinoma identified by massively parallel sequencing. Proceedings of the National Academy of Sciences of the United States of America. 2011; 108: 18032-18037.

[105] Moore K, Colombo N, Scambia G, Kim BG, Oaknin A, Friedlander M, et al. Maintenance Olaparib in Patients with Newly Diagnosed Advanced Ovarian Cancer. The New England Journal of Medicine. 2018; 379: 2495-2505.

[106] DiSilvestro P, Colombo N, Scambia G, Kim BG, Oaknin A, Friedlander M, et al. Efficacy of Maintenance Olaparib for Patients with Newly Diagnosed Advanced Ovarian Cancer with a BRCA Mutation: Subgroup Analysis Findings from the SOLO1 Trial. Journal of Clinical Oncology. 2020; 38: 3528-3537.

[107] González-Martín A, Pothuri B, Vergote I, DePont Christensen R, Graybill W, Mirza MR, et al. Niraparib in Patients with Newly Diagnosed Advanced Ovarian Cancer. New England Journal of Medicine. 2019; 381: 2391-2402.

[108] Coleman RL, Fleming GF, Brady MF, Swisher EM, Steffensen $\mathrm{KD}$, Friedlander M, et al. Veliparib with first-Line Chemotherapy and as Maintenance Therapy in Ovarian Cancer. New England Journal of Medicine. 2019; 381: 2403-2415.

[109] Ray-Coquard I, Pautier P, Pignata S, Pérol D, GonzálezMartín A, Berger R, et al. Olaparib plus Bevacizumab as FirstLine Maintenance in Ovarian Cancer. New England Journal of Medicine. 2019; 381: 2416-2428.

[110] Byrne AT, Ross L, Holash J, Nakanishi M, Hu L, Hofmann JI, et al. Vascular endothelial growth factor-trap decreases tumor burden, inhibits ascites, and causes dramatic vascular remodeling in an ovarian cancer model. Clinical Cancer Research. 2003; 9: $5721-5728$.

[111] Perren TJ, Swart AM, Pfisterer J, Ledermann JA, PujadeLauraine E, Kristensen G, et al. A Phase 3 Trial of Bevacizumab in Ovarian Cancer. New England Journal of Medicine. 2011; 365: 2484-2496.

[112] Tewari KS, Burger RA, Enserro D, Norquist BM, Swisher EM, Brady MF, et al. Final Overall Survival of a Randomized Trial of Bevacizumab for Primary Treatment of Ovarian Cancer. Journal of Clinical Oncology. 2019; 37: 2317-2328.

[113] Burger RA, Brady MF, Bookman MA, Fleming GF, Monk $\mathrm{BJ}$, Huang $\mathrm{H}$, et al. Incorporation of Bevacizumab in the Primary Treatment of Ovarian Cancer. New England Journal of Medicine. 2011; 365: 2473-2483.

[114] Reverdy T, Sajous C, Péron J, Glehen O, Bakrin N, Gertych $\mathrm{W}$, et al. Front-Line Maintenance Therapy in Advanced Ovarian Cancer-Current Advances and Perspectives. Cancers. 2020; 12: 2414.

[115] Banerjee S, Gonzalez-Martin A, Harter P, Lorusso D, Moore $\mathrm{KN}$, Oaknin A, et al. First-line PARP inhibitors in ovarian cancer: summary of an ESMO Open - Cancer Horizons round-table discussion. ESMO Open. 2020; 5: e001110.

[116] Penn CA, Wong MS, Walsh CS. Cost-effectiveness of Maintenance Therapy Based on Molecular Classification Following Treatment of Primary Epithelial Ovarian Cancer in the United States. JAMA Network Open. 2020; 3: e2028620.

[117] D'Andrea AD. Mechanisms of PARP inhibitor sensitivity and resistance. DNA Repair. 2018; 71: 172-176. 